\title{
Golgi staining-like retrograde labeling of brain circuits using rabies virus: Focus onto the striatonigral neurons
}

\author{
Salin $\mathbf{P}^{1^{*}}$, Blondel $\mathrm{D}^{2}$, Kerkerian-Le Goff $\mathbf{L}^{\mathbf{1}}$ and Coulon $\mathbf{P}^{3}$ \\ 1 Aix Marseille Univ, CNRS, IBDM, Marseille, France \\ 2 Institute for Integrative Biology of the Cell (I2BC), CEA, CNRS, Univ. Paris-Sud, Universite Paris- \\ Saclay, 91198 Gif-sur-Yvette cedex, France \\ 3 Institut de Neurosciences de la Timone, Aix-Marseille Université and CNRS, Marseille, France \\ * corresponding author
}

\section{Highlights:}

Viral tract-tracing is an added value for multidimensional study of the connectome

Chains of connected neurons can be visualized in a Golgi staining-like fashion

SAD and CVS rabies virus strains allow detailed visualization of dendritic morphology

A new fluorescent transneuronal recombinant of CVS-N2c provides Golgi-like labeling

\begin{abstract}
Background

The introduction of viral transneuronal tracers in the toolbox of neural tract-tracing methods has been an important addition in the field of connectomics for deciphering circuit-level architecture of the nervous system. One of the added values of viral compared to conventional retrograde tracers, in particular of rabies virus, is to provide a Golgi staining-like view of the infected neurons, revealing the thin dendritic arborizations and the spines that are major post-synaptic seats of neuronal connections.
\end{abstract}

New method

Here, we comparatively illustrate the characteristics of the labeling obtained in the same model system, the basal ganglia circuitry, by different retrograde viral tracing approaches, using the Bartha strain of pseudorabies virus, the SAD and CVS strains of rabies virus and by the conventional retrograde tracer cholera toxin $\mathrm{B}$. To best contrast the differences in the capacity of these tracers to reveal the dendritic morphology in details, we focused on one population of first-order infected neurons in the striatum, which exhibit high spine density, after tracer injection in the substantia nigra.

Results and conclusion

None of the viruses tested allowed to detect as many neurons as with cholera toxin B, but the SAD and CVS strains of rabies virus had the advantage of enabling detailed Golgi-like visualisation of the dendritic trees, the best numerical detection being offered by the transneuronal rCVS-N2c-P-mCherry while poor labeling was provided by rCVS-N2c-M-GFP. Results also suggest that, besides different viral properties, technical issues about constructs and detection methods contribute to apparently different efficiencies among the viral approaches.

\section{Key Words}

Retrograde tract-tracing; Rabies virus; transneuronal; Golgi-like; Basal Ganglia; Striatal medium-sized spiny neuron 


\section{Introduction}

Tract-tracing approaches, together with electrophysiology and electron microscopy, are powerful experimental tools to unveil the connectivity of neurons whose coordinated activity underlies brain circuit function. Advances in this field have greatly benefited from the expanding exploitation of viruses (Lanciego and Wouterlood, 2020). In particular, the development of viral transneuronal tracing methods, which use the capacity of some neurotropic viruses to propagate sequentially across connected neurons and to function as self-amplifier in the infected neurons, has made it possible to delineate chains of neurons within specific networks. The visualization of the neuronal dendrites, in particular of their spines, is crucial to understand the organization and plasticity of neuronal circuits. Dendritic spines, first described by Santiago Ramón y Cajal in 1888 (Cajal, 1888), are the postsynaptic sites of most excitatory synapses in the central nervous system and are dynamic structures that can exhibit changes in shape and number in physiological and pathological conditions (Berry and Nedivi, 2017). The gold standard to detect the fine details of neuronal dendritic arborization is still the silver staining technique that has been used by Cajal, called Golgi metallic impregnation method. This method or its updates (Rapid Golgi staining, Golgi-Cox method) allows staining a limited number of neurons in their entirety, in a still unexplained random manner. The transneuronal retrograde tracers, particularly rabies virus (RABV), have the advantage of enabling both the detection of neurons based on their connectivity and the morphological characterization of their dendritic processes, which is an added value for multi-dimensional studies in combination with other neuroanatomical techniques.

Available viral retrograde transneuronal tracers include the herpes simplex virus type 1 , the pseudorabies virus (PRV) and RABV, this latter and its recombinants being currently the most widely utilized. Worldwide, the use of RABV as a marker of neural networks is mainly based on two 'fixed' strains (Figure 1A) coming from 'street' rabies virus isolated from i) a rabid cow in 1882 (Paris): The Challenge Virus Standard (CVS) and ii) a rabid dog in 1935 (USA): Street-Alabama-Dufferin (SAD) virus. Several CVS subtypes are available, including CVS-11 and variants of CVS-24 (as CVS-N2c). These fixed strains have been adapted from the street ones by repeated passages first in mice brains and then in cell cultures, leading to the selection of strains with stable properties. The first use of CVS11 as neuronal tracer was reported by Astic and collaborators in the olfactory network (Astic et al., 1993), followed by a study from Ugolini (Ugolini, 1995) with injection in the hypoglossal nerve to reveal, by immunodetection of the viral nucleocapsids, the spread of the virus over time in the interconnected neurons. This latter study was a follow-up of series of experiments using the transsynaptic property of the herpes simplex virus type 1 or PRV to decipher neural networks (AstonJones \& Card, 2000; Card et al., 1990; Card \& Enquist, 2014; Ugolini et al., 1989). Due to some limitations of PRV, such as its uptake by fibers of passage, neurotoxicity and glia infection at advanced stages, data from experiments using RABV incrementally increased at the expense of those using PRV. After molecular cloning of RABV SAD B19 (Conzelmann et al., 1990; Schnell et al., 1994) the second key advance for the use of RABV has been the development of different recombinant variants of SAD B19 (Ceccaldi et al., 1998; Etessami et al., 2000) and the selection of CVS-N2c variant (Morimoto et al., 1998), highlighting the crucial role of the RABV envelope glycoprotein (G-protein) in the viral infection in neurons. Design and generation of recombinant RABV vectors with deletion of the G-protein-coding sequence from the SAD B19 genome and inclusion of fluorescent reporter genes (Wickersham et al., 2007a, b) have given new tools to study the neuronal networks. Indeed, G-deleted $(\Delta \mathrm{G}) \mathrm{RABV}$ coated with its G-protein can infect neurons from their presynaptic terminals but loses its transsynaptic property (Etessami et al., 2000). It became a useful first-order retrograde tracer (Wickersham et al., 2007a), and a potent monosynaptic retrograde marker following in vivo trans-complementation with $G$ within the infected neurons either from a plasmid, a helper virus, or a mouse transgene. The next step has been to direct the primary infection to a genetically-targeted neuronal population and to restrict the viral spread to the presynaptic neurons connecting this population, which overcame key limitations in the use of transsynaptic tracers by enabling unambiguous tracing of monosynaptic inputs to specific cell types. Recombinant $\Delta \mathrm{G}-\mathrm{SAD}$ B19 pseudotypes, which carry the envelope protein of an avian retrovirus (EnvA), have been created to make the RABV unable to infect mammalian cells unless they have been engineered to express EnvA's receptor, 'TVA', and the ability of the virus to spread to the monosynaptically connected 
neurons has been conferred by Trans-complementation with $\mathrm{G}$ within the primary infected neurons (Wickersham et al., 2007b). This RABV-based monosynaptic tracing approach, which has also the advantage of safety for the users, has been extensively applied in mapping circuits in various parts of the nervous system (for review see Callaway \& Luo, 2015). In parallel, recombinant CVS-N2c called $\mathrm{rN} 2 \mathrm{c}$, containing the synthetic codon-optimized or -deoptimized versions of the N2c G gene have been developed on mouse neurobastoma cells (Morimoto et al., 2000, 1999, 1998), showing that G-protein expression level is not critical in viral pathogenicity (Wirblich and Schnell, 2011). More recently, recombinant $\Delta \mathrm{G}-\mathrm{CVS}-\mathrm{N} 2 \mathrm{c}$ has been shown to exhibit enhanced retrograde transfer compared with $\triangle$ G-SAD B19 (Reardon et al., 2016). On the other hand, new chimeric glycoprotein variants have been generated to improve monosynaptic tracing with $\triangle \mathrm{G}-\mathrm{SAD}$ B19 (Kim et al., 2016). These studies provided additional evidence that the CVS strain of RABV is far more infectious that SAD B19.

This paper aims at characterizing the propagation and Golgi-like staining properties of CVS-11 in comparison with other retrograde viral tracers, either first-order or transsynaptic, including two fluorescent rN2c, rCVS-N2c-P-mCherry (Nikolic et al., 2017, 2016) and rCVS-N2c-M-GFP (unpublished) (Figure 1B), recently engineered by Blondel and collaborators to avoid the step of immunodetection of CVS. We have chosen as a common study model the basal ganglia, a set of brain structures engaged in loop circuits with the cerebral cortex, which fulfill essential role in adaptive control of motor, cognitive, and motivational behavior and are involved in the pathophysiology of movement disorders and different neuropsychiatric disorders (Jellinger, 2019a,b; Macpherson \& Hikida, 2019). The striatum represents the main input station of the basal ganglia. The great majority (> 90\%) of the striatal neurons are GABAergic projection neurons, called medium-sized spiny neurons (MSNs), given the great numbers of spines studding their dendrites. They are segregated into two numerically equivalent populations with different neuronal targets and neurochemical features: i) the striatonigral neurons, which express dopamine D1 receptor and the neuropeptides substance P and dynorphin and ii) the striatopallidal neurons that express dopamine D2 receptors and enkephalin (Gerfen and Scott Young, 1988). These two populations are respectively at the origin of the so called 'direct' and 'indirect' pathways by which the striatum regulates the activity of the substantia nigra (SN) pars reticulata, the main basal ganglia output structure in rodents. In the classical model proposed in the 90's (Albin et al., 1989; Alexander and Crutcher, 1990), the direct and indirect pathways have an opposite balancing role in the control of motor behaviour. Although being increasingly challenged, this model provided striking predictions about basal ganglia dysfunction in movement disorders (Calabresi et al., 2014; Quartarone et al., 2019). In addition to their extrastriatal projection sites, axons of MSNs also profusely branch within the striatum, with subtype specific distribution of their collaterals within or outside the area occupied by the dendritic field of the cell of origin (Bishop et al., 1982; Van Dongen et al., 2008). The connections they form with other MSNs have been reported to show subclass-dependent asymmetries in probability and strength (Taverna et al., 2008) and the functional relevance of the lateral inhibition emerging from the collateral transmission between these neurons, long considered as weak, has been recently emphasised (for review see Burke et al., 2017). The striatal projection neurons receive several extrinsic inputs, notably from pyramidal cortical neurons, as well as intrinsic inputs from striatal interneurons, allowing to evaluate the transsynaptic propagation efficiency of the different viruses tested. Besides their well-known connectivity, these neurons have highly spiny dendritic arborization, which are advantages in our comparative analysis of the ability of the different tracers to provide Golgi-like staining of primary infected neurons. To study the viral propagation while avoiding any problem of contamination from the injection site, we focused on the connectivity of striatonigral neurons, which are long distance projecting neurons compared to the striatopallidal ones. Figure 2 schematizes the virus propagation in the network (2B) and gives illustrative examples of the staining observed in the injected substantia nigra (2A), the striatum (2D) and the cerebral cortex (2C). All the original results presented concern the dorsal striatum.

\section{Materials and methods}

Experiments were carried out in adult male Wistar rats (6 weeks old), adult male C57Bl/6 mice (10 weeks old) and Drd1a-tdTomato line 6 BAC transgenic mice in which the striatonigral neurons are 
identified by D1 dopamine receptor promotor-specific fluorescent reporter (Ade et al., 2011). Surgical procedures adhered to the European guidelines for the care and use of laboratory animals (EU Directive 2010/63) and were approved by the ethics committee in Neurosciences at the Institut de Neurosciences de la Timone, INT-Marseille ( $n^{\circ}$ 02167-01). Vaccinated personnel conducted all rabies viruses handling, surgery, injection and animal care procedures at the appropriate biosafety containment level (level 2) at the INT.

2.1. Neural tracers. The rabies virus mainly used in the experiments was the French isolate of fixed strain CVS-11 (figure 2; Ugolini 2010). The unmodified CVS-11, amplified in BSR cells, was used as a cell culture supernatant in minimal essential medium, titrated at $4 \times 10^{7}$ plaque forming units (pfu) $/ \mathrm{ml}$.

The recombinant strain of CVS-24 N2c expressing a Phospho-mCherry fusion protein (rCVS-N2c-Pmcherry) and the one with the Matrix-GFP fusion protein (rCVS-N2c-M-GFP) were used at $5 \times 10^{7}$ $\mathrm{pfu} / \mathrm{ml}$ and $2 \times 10^{7} \mathrm{pfu} / \mathrm{ml}$ respectively. The full-length recombinant $\mathrm{N} 2 \mathrm{c}$ (prN2c) infectious clone was described previously (Wirblich and Schnell, 2011). The authentic phosphoprotein (P) or matrix-protein (M) coding sequence was replaced with the P-mCherry or M-GFP fusion encoding sequence, respectively (Figure 1B). The rCVS-N2c-P-mCherry has been described previously (Nikolic et al. 2016). For rCVS-N2C-M-GFP, the M-GFP fusion was generated by insertion of the e-GFP downstream the residue 26 of the $\mathrm{M}$ protein, which is located in the disordered $\mathrm{N}$ terminus of $\mathrm{M}$ (Graham et al., 2008) as described for VSV to obtain a viable M-eGFP fusion protein (Soh and Whelan, 2015). In brief, the GFP gene was first inserted downstream the nucleotide 78 of the $M$ gene in the pCDNA3.1 vector (Invitro gene). Then two overlapping fragments were amplified by PCR: the first one going from the Spe1 site of the full-length genomic plasmid prN2c to the end of the M-GFP and the second one from the end of M to the PST1 site located at the end of the G gene coding sequence. The genomic plasmid which has been digested with Spe1 and Pst1 restriction enzymes and the PCR products were assembled using Gibson Assembly kit (New England Biolabs).

Recombinant viruses were recovered as described previously (Fouquet et al., 2015; Wirblich et al., 2008). Briefly, N2A cells ( $10^{6}$ cells) were transfected using lipofectamine 2000 (Invitrogen) with 0.85 $\mu \mathrm{g}$ of full-length rCVS P-mCherry or rCVS-M-GFP, in addition to $0.4 \mu \mathrm{g}$ pTIT-N, $0.2 \mu \mathrm{g}$ pTIT-P, 0.2 $\mu \mathrm{g}$ pTIT-L and $0.15 \mu \mathrm{g}$ pTIT-G, which encode respectively the $\mathrm{N}, \mathrm{P}, \mathrm{L}$ and $\mathrm{G}$ proteins of CVS-N2C RABV strain. These plasmids were cotransfected with $0.25 \mu \mathrm{g}$ of a plasmid encoding the T7 RNA polymerase. Six days post-transfection, the supernatant was passaged on fresh N2A cells, and infectious recombinant viruses were detected three days later by the fluorescence of the P-mCherry protein or M-GFP.

The fluorescent recombinant $\Delta \mathrm{G}$ SAD B19 coated with its G-protein (SAD $\Delta$ G.eGFP) [generous gift from K.K. Conzelmann; (Hagendorf and Conzelmann, 2015)] was injected at $3 \times 10^{8} \mathrm{pfu} / \mathrm{ml}$.

The Bartha strain of GFP-pseudorabies virus (Bartha GFP-PRV), a gift from T.C. Mettenleiter (Jöns and Mettenleiter, 1997) was injected at $5 \times 10^{6} \mathrm{pfu} / \mathrm{ml}$.

Cholera toxin subunit B (CTB) conjugated to Alexa Fluor 594 (Life technologies, Cat\# C34777) was injected at the concentration of $1 \mu \mathrm{g} / \mu \mathrm{l}$ in phosphate buffered saline.

Experiments were conducted on at least 20 animals for CVS-11, groups of 8-12 animals for SAD $\Delta$ G.eGFP, rCVS-M-GFP, rCVS P-mCherry, and 3-5 animals for Bartha GFP-PRV and for CTB. The kinetic study for CVS-11 was performed on subgroups of 4 rats at each time point post-injection and the study of the co-expression with D1 receptor was done on 6 transgenic mice.

2.2. Surgical procedure. Surgery was performed under ketamine+xylazine anesthesia (intraperitoneal injections, 100 and $10 \mathrm{mg} / \mathrm{kg}$, respectively). The animals, placed in a stereotaxic frame (David Kopf Instruments), received a unilateral injection of the tracer in the SN. For the rat, the stereotaxic coordinates of the injection site were (from the interaural) anteroposterior (AP) $+2.2 \mathrm{~mm}$, lateral (L) $2.0 \mathrm{~mm}$ and dorsoventral (DV) $+3.3 \mathrm{~mm}$, with the incisor bar at $+5.0 \mathrm{~mm}$ above the interaural plane, according to the atlas by De Groot (1959), and for the mice (from bregma coordinates) AP: $+2.8 \mathrm{~mm}$, $\mathrm{L}: 1.35 \mathrm{~mm}$ and DV: $+4.35 \mathrm{~mm}$, with the incisor bar at $-1.0 \mathrm{~mm}$ above the interaural plane, according to the atlas by Paxinos and Franklin (2001). Each tracer was pressure-injected in a final volume of 300 $\mathrm{nl}$ for the rat and $200 \mathrm{nl}$ for the mouse at a flow rate of $100 \mathrm{nl} / \mathrm{min}$ using a programmable injector. 
2.3. Histology. Animals were processed for histology at the following time points after injection of the tracers: 10 days for CTB, 24, 42 and $72 \mathrm{~h}$ for CVS-11 and 40-42h for the other viruses. They were anesthetized with an overdose of ketamine and xylazine and then intracardially perfused with a saline solution (50 ml for rat, $5 \mathrm{ml}$ for mouse) followed by a fixative solution containing $4 \%$ paraformaldehyde (PFA) in $0.125 \mathrm{M}$ phosphate buffer, $\mathrm{pH} 7.4$ (300 $\mathrm{ml}$ for rat, $30 \mathrm{ml}$ for mouse). After perfusion, the skull was opened and the dissected brain was post-fixed in PFA (4\%) overnight at $4{ }^{\circ} \mathrm{C}$ and then placed in a $30 \%$ sucrose solution for $48 \mathrm{~h}$. The brains were frozen in powder dry ice and stored at $-80^{\circ} \mathrm{C}$. Coronal $\left(40 \mu \mathrm{m}\right.$ thick) tissue sections were cut at $-20^{\circ} \mathrm{C}$ with a cryostat $(\mathrm{CM} 3050 \mathrm{~S}$, Leica), collected in cryoprotective solution and stored at $-20^{\circ} \mathrm{C}$. The immunodetection of the unmodified CVS-11 rabies virus was done with an antibody (31G10) directed against viral P-protein (Raux et al., 1997) that spreads throughout the cytoplasm of RABV-infected neurons (Salin et al., 2008). The brain sections were incubated for $12 \mathrm{~h}$ in a mouse anti-RABV P-protein monoclonal antibody diluted 1:10,000 in PBS. After rinsing, the sections were incubated for $2 \mathrm{~h}$ with the secondary antibody donkey anti-mouse IgG coupled to Alexa Fluor 594 or Alexa Fluor 488 diluted 1:200 (Jackson ImmunoResearch Europe, Inc.). For rCVS-M-GFP, immunodection of GFP was performed in an experiment for the signal amplification. In brief, sections were incubated overnight with a chicken anti-GFP antibody diluted 1:500 (Aves Labs Inc., USA). After rinsing, they were incubated with a secondary fluorescent antibody, donkey anti-chicken IgG coupled to Alexa Fluor 594 diluted 1:200 (Jackson ImmunoResearch Europe, Inc.). In another experiment, the P protein of rCVS-M-GFP was immunodetected as described above, using the donkey anti-mouse secondary antibody coupled to Alexa Fluor 594.

The sections were then mounted on SuperFrost Plus glass slides (ThermoFisher Scientific). The staining examination focused mainly on the striatum and the overlaying motor cortical areas.

Golgi staining was performed on 4-mm thick coronal blocks of brain tissue including the striatum, using FD Rapid GolgiStain Kit (NeuroTechnologies Inc.) based on Golgi-Cox impregnation. Blocks were then frozen and processed for cryostat sectioning ( $40 \mu \mathrm{m}$ thick sections) as detailed by the manufacturer. Light microscope observations were performed on sections from 3 animals.

In brain sections of mice injected with rCVS-N2c-P-mCherry, the two neurochemically distinct compartments of the striatum, namely the striosomes -also termed patches- and the matrix, were revealed by immunodetection of the mu opioid receptor (highly expressed in striosomes). Sections were incubated with a monoclonal rabbit anti-mu opioid receptor antibody (1/1000; Abcam ab134054), followed by goat anti-rabbit IgG coupled to Alexa Fluor 488 (Jackson ImmunoResearch Europe, Inc.).

Except for Golgi staining, brain sections were examined under a confocal microscope (LSM 780, Carl Zeiss) and the acquired images were processed using Adobe Photoshop.

\section{Results and Discussion}

\subsection{Lack of staining at the site of RABV injection}

Upon injection in the brain, RABV is quickly sequestered within permissive neuronal terminals. The lack of accumulation of the virus prevents precise determination of the RABV spread at the injection site (Ugolini, 2010). Accordingly, at all the time points that we have considered ( $24 \mathrm{~h}, 42 \mathrm{~h}$ and $72 \mathrm{~h}$ ), no specific viral labeling is detected at the site of injection of CVS-11 (Figure $2 \mathrm{~A}$ ). The absence of staining at the injection site complies with most in vivo studies reporting that glial cell infection by RABV is not prominent in the CNS. It is also consistent with the fact that interneurons have not been identified in the SN and that axon collaterals of projection neurons, although providing feedback inhibition (Brown et al., 2014), are very sparse (Mailly et al., 2003). Surprisingly, by co-injecting methylene blue aqueous solution with CVS-11 to visualize the injection area, we observed RABV accumulation at the injection site in an area restricted to the SN. This accumulation, together with the 
lack of RABV-positive neurons in the striatum (not shown), suggests that the presence of methylene blue prevents infection by the virus.

\subsection{Time course of the RABV staining using CVS-11}

It has been previously reported that labeling of first-order neurons usually requires up to 2 days after $\mathrm{RABV}$ injection at peripheral sites and that subsequent successive transneuronal transfer to higherorder neurons occurs at regular intervals of at least 12h (Coulon et al., 2011; Tang et al., 1999; Ugolini, 2011, 2010). Here, immunodetection of unmodified CVS-11 was carried out at 24, 42 and 72 $\mathrm{h}$ post-injection.

At $24 \mathrm{~h}$, a significant number of striatal neurons and very few scattered neurons in cortical layer 5 are labeled, although faintly. The staining pattern is similar to the one that can be obtained with CTB and with the recombinant SAD $\triangle$ G.eGFP, indicating that, at this time point, only the primary infected neurons projecting to the $\mathrm{SN}$ are detected. The sparse neuronal labeling in the cortex is consistent with previous data reporting weak corticonigral projections (Naito and Kita, 1994; Watabe-Uchida et al., 2012). In both the striatum (Figure 3A1, A2) and the cerebral cortex (Figure 3B1), the intracellular labeling is largely restricted to the cell body and proximal dendrites, detection of dendritic spines being only casual. The perikarya of infected neurons show non-uniform labeling with intenselystained round inclusion bodies that are called Negri bodies. These structures, typical of RABV infection, are sites of viral transcription and replication containing all the replication machinery proteins (L, N and the P protein) and viral RNA (Lahaye et al., 2009). In addition, Negri bodies have been recently described as liquid droplets formed by phase separation (Nikolic et al., 2017).

At $42 \mathrm{~h}$, the numbers of detected neurons increased in the striatum (Figure 3A3) and even more in the cerebral cortex (Figure 3B2) compared to $24 \mathrm{~h}$. In both territories, first-order labeling is increased, enhancing the detection of primary-infected neurons. In addition, second-order less intense labeling is detected. In the cortex, the great majority of RABV-positive neurons seats in layer 5 . Their staining is attributable mostly to transsynaptic infection by RABV of the cortical projection neurons connecting the primary infected striatonigral neurons, as indicated by comparison with the few cortical neurons detected after injection of the retrograde tracers SAD $\Delta$ G.eGFP and CTB. In the striatum, the labeled neurons are in majority spiny neurons that are likely the primary-infected striatonigral neurons. Their cytoplasm is now homogenously labeled, without individualized Negri bodies, presumably due to recognition of $\mathrm{P}$ protein within or outside Negri bodies by the antibody used. They exhibit intense Golgi-like staining, allowing detailed visualization of their dendritic tree and specialisations such as spines. By contrast, only the proximal segment of their axon can be detected, consistent with previous work reporting that viral proteins do not spread in the axon extent (Ugolini, 1995). The fewer secondorder infected neurons do not show spines and exhibit Negri bodies, and were previously reported to mainly include cholinergic and parvalbumin interneurons (Salin et al., 2009).

To further characterize the infected neurons at this time point, intranigral injection of CVS-11 was performed in Drd1a-tdTomato line 6 mice. In these mice, td-Tomato fluorescence has been reported to be highly specific to striatonigral neurons, since the most abundant interneuron types do not exhibit detectable level of fluorescence and only around 2\% of the neurons co-express D1 and D2 in Drd1atdTomato $^{+/} /$Drd2-EGFP ${ }^{+/}$mice (Ade et al., 2011). The great majority of the RABV-labeled neurons at $42 \mathrm{~h}$ post-viral inoculation are D1 receptor-expressing MSNs (Figure 4A), confirming that they belong to the striatonigral population. Quantitative analysis shows that $87.6 \pm 2.23 \%$ over $789 \mathrm{RABV}$ labeled neurons are expressing D1 receptor (3 mice, 4 sections examined per animal). The $12 \%$ of RABV-positive striatal neurons that do not express D1 receptor are weakly labeled neurons, in which the visualization of the dendritic arborization is limited, presumably corresponding to second-order neurons. Populations of striatal interneurons are likely to constitute most of this pool of second-order neurons, as we previously reported that for each 100 striatonigral RABV-positive neurons counted, around 3 are cholinergic and 9 are parvalbumine GABAergic interneurons (Salin et al., 2009). The complementary experiment in which CVS-11 is injected in the globus pallidus of Drd1a-tdTomato line mice ( $\mathrm{n}=3$ animals) to label striatopallidal neurons from their terminals shows that, with very few exceptions, RABV-infected striatal neurons are not D1-expressing neurons (Figure 4B). Cross- 
connections between the striatonigral and striatopallidal neurons, via axon collaterals are thus unlikely to contribute significantly to the pool of second-order infected neurons in the striatum at $42 \mathrm{~h}$ postinjection of the virus in either striatal target.

At $72 \mathrm{~h}$, the density of positive neurons and the tangles of neurites in the striatum are so important that it is now difficult to individualize the neurons and their dendritic extension (Figure 3A4). In the cerebral cortex (Figure 3B3), numerous neurons are labeled in layers 2-6. At this time point, considering its replication and transfer kinetics, the RABV has passed 4-5 synapses, which make it impossible to interpret the results given the rich connectivity of the basal ganglia. Such delay postinfection appears unsuitable to decipher the chain of connections within a given neuronal network in the rodent central nervous system.

Therefore, a time window around 2 days post-injection appears as the most appropriate to properly delineate the multisynaptic circuits in our model system, allowing both Golgi-like visualization of the first-order neurons and good detection of at least second-order neurons. To note that no major differences in the viral staining between mouse and rat was observed in our experiments.

\subsection{Differences in staining among retrograde viral tracers at 42 h post-injection}

Differences in neurotropism among retrograde viral tracers have long been demonstrated. More recent work, comparing tracing characteristics of such viruses in the same model systems, showed region preferences in their neurotropic properties (Sun et al., 2019). Here, the tracing characteristics of Bartha GFP-PRV, SAD $\triangle$ G.eGFP, rCVS-N2c-P-mCherry and rCVS-N2c-M-GFP were compared to that of unmodified CVS-11, at $42 \mathrm{~h}$ post-injection in the SN.

The Bartha GFP-PRV was a commonly used tracer to delineate multi-synaptic central circuits from peripheral targets (Card \& Enquist, 2014). It has been rarely applied to trace basal ganglia connectivity. Its injection in the SN leads to a significant labeling of striatonigral neurons at $42 \mathrm{~h}$ postinjection, but no cortical labeling. Compared to RABV injection at the same time point, the PRV is less efficient and does not provide nice Golgi-like labeling: the number of stained striatal neurons is lower and only few dendritic branches and sparse spines are visualized (Figure 5A). The marked differences between the Bartha GFP-PRV and the RABV staining could be due to differences in the titers of the viruses, the slowness of the PRV replication or to differences in the intraneuronal localisation of the fluorophore.

Using $\mathrm{SAD} \Delta \mathrm{G}$.eGFP as first-order retrograde viral tracer, numerous stained striatal neurons and very few cortical neurons are visualised. Compared to CVS-11 or rCVS-N2c-P-mCherry, SAD $\Delta$ G.eGFP provides similar intraneuronal staining intensity, with a nice Golgi-like visualisation of dendritic arborizations and spines (Figure 5B), but fewer striatal positive neurons are detectable (Figure 6A compared to 6B-C). Although the lack of transsynaptic labelling of striatal neurons connected to the primary-infected striatonigral neurons with $\mathrm{SAD} \Delta \mathrm{G}$.eGFP could contribute in part to the differences with the transsynaptic CVS used, the present observations are in agreement with previous reports showing that the SAD B19 is less efficient to infect neurons compared to CVS (Kim et al., 2016; Reardon et al., 2016; Zhu et al., 2019). However, once in the neuron, it presumably shows viral replication potency similar to CVS, as suggested by the comparable Golgi-like staining.

Injection of rCVS-N2c-P-mCherry induces after $42 \mathrm{~h}$ a strong Golgi-like staining of a large number of striatal neurons (Figures 5C, 6C) and intense labeling of numerous cortical neurons, mainly in layer 5. The numbers of infected neurons in both the striatum and the cortex are approaching those seen $72 \mathrm{~h}$ rather than $42 \mathrm{~h}$ after CVS-11 injection. However, the layer pattern of cortical labeling is similar to the one observed at $42 \mathrm{~h}$ post-injection of CVS-11 (Figure 2D), suggesting that labeled neurons are mostly second-order infected corticostriatal neurons. Previous studies have suggested a higher transneuronal transfer rate of CVS 24 N2c compared to CVS-11 (Callaway, 2008). Although we cannot rule it out, our data rather support higher infection capacity or replication rate of rCVS-N2c-P-mCherry than of 
CVS-11. Studying in details the kinetics of transfer of rCVS-N2c-P-mCherry for identifying the order of connections in comparison with CVS-11 is required to further address this issue.

Injection of rCVS-N2c-M-GFP leads to suboptimal staining compared to CVS-11 or even more to rCVS-N2c-P-mCherry, both numerically and qualitatively, suggesting at first sight that this recombinant is much less infectious (Figure 5D). This is consistent with the results obtained for the recombinant VSV M-GFP which has been shown to be attenuated with regard to viral replication and viral growth (Soh and Whelan, 2015). It can be assumed that the insertion of the fluorophore inside the $\mathrm{M}$ protein is not inert and results in reduced infectivity or/and speed of replication/propagation of this RABV recombinant. In contrast, SAD $\Delta$ G.eGFP, in which GFP replaces the viral glycoprotein gene, is known to be stable. However, immunodetection of the GFP is shown to amplify the labeling obtained with rCVS-N2c-M-GFP, indicating that the native fluorescence underestimates the level of GFP expression and thus the number of infected neuron detected (Figure 7A). Interestingly, immunodetection of the P-protein of rCVS-N2c-M-GFP with the RABV anti-P monoclonal antibody (Figure 7B) also reveals higher numbers of infected neurons, confirming that the level of GFP expression underestimates the degree of viral infection, and, more importantly, shows greater details of their dendritic arborization, such as visualization of spines, which could be due to the different expression levels and localization of the viral $\mathrm{P}$ and $\mathrm{M}$ proteins. It can be then concluded that detection issues rather than infectivity account for the poorer direct labeling obtained rCVS-N2c-M-GFP.

Besides avoiding the step of immunodetection of CVS, rCVS-N2c-P-mCherry and rCVS-N2c-M-GFP have been engineered with the aim to address an additional complexity level in the brain networks' connectivity diagrams by the combination of viral tracers with similar strain properties in single animals. For example, by injecting one of the recombinant viruses in one target of a given brain structure and the other in another target of the same structure, we aimed at investigating the issue of parallel or integrated information processing in subcircuits within the network, by the absence or presence of dually-stained primary and/or higher-order traced neurons. Regarding the basal ganglia model system, it is recognized that the striatonigral and striatopallidal neuronal populations are highly segregated. However, it remains unknown whether the inputs they receive from identified populations of striatal interneurons or from extrinsic sources arise from the same neurons or from segregated subpopulations. Successful application of such dual transneuronal tracing requires that the two viruses infect a neuron within a narrow time window (few hours) due to virus interference that decreases the efficiency of the second infection in a time dependent manner (Ohara et al., 2009). The failure of rCVS-N2c-M-GFP to provide satisfactory staining per se did not allow us to achieve such an objective. Recently, multiplex G-deleted RABV tracing has been developed to simultaneously label and characterize multiple circuits in single animals (Suzuki et al., 2020).

\subsection{CTB versus RABV labeling}

The injection of the fluorescent retrograde tracer CTB in the SN shows a large population of labeled striatal neurons and very few cortical neurons. Even though the staining is intense, it is restricted to the cell body cytoplasm (Figure 5F), contrasting with the Golgi-like labeling resulting from RABV infection, as illustrated for rCVS-N2c-P-mCherry (Figure 5C) or CVS-11 (Figure 5F) at $42 \mathrm{~h}$ post injection. However, for a similar volume of injection, the number of striatal CTB-positive neurons is always greater than the number of RABV-infected neurons, consistent with wider diffusion of CTB than RABV in the injection site, as already reported in previous studies (Ugolini, 2010).

\subsection{Golgi-like staining with $R A B V$}

Since the publication of the seminal work by Santiago Ramón y Cajal (Cajal, 1893), Golgi impregnation remains one of the most reliable histological techniques enabling the detailed visualization of the entire morphology of neurons, including dendritic spines. However, stains based on the Golgi method do not allow distinguishing neurons with quite identical morphology, such as the two populations of striatal projection neurons, and can hardly be combined with other labeling methods. Together with the randomness of staining, these are major limitations for mapping neuronal circuits. Advances in the tools allowing a Golgi-staining like labeling include intracellular labeling 
methods, the development of various retrograde tracers and of virus vectors and the generation of transgenic mice, such as the Thyl-XFP mice (in which XFP stands for any fluorescent protein) in which projections neurons are labeled in many parts of the nervous system, notably deep cortical projection neurons. The Golgi-like labeling in Thyl-XFP mice is used in numerous studies to visualize dendritic spines and explore their plasticity (Feng et al., 2000) and has been combined with tracttracing techniques (Porrero et al., 2010).

Transneuronal retrograde tracing methods using RABV can offer the advantage to associate charting of serially connected neurons and powerful detection of the dendritic structure. The fluorescent RABV-recombinant rCVS-N2c-P-mCherry leads to an impressive Golgi-like labeling of primaryinfected striatonigral neurons, as did $\mathrm{SAD} \Delta \mathrm{G}$.eGFP, but also of second-order corticostriatal projection neurons, as also seen by immunodetection of CVS-11. Figure 8 illustrates the morphology of a striatal MSN and of a cortical pyramidal neuron revealed by the classical Golgi impregnation method (Figure 8A) and by the viral tracing approach using rCVS-N2c-P-mCherry (Figure 8B). The resolution is quite comparable, allowing detailed visualization of thin dendrites and dendritic spines, such as the spines seating on the secondary branches of the extended apical dendrite of the pyramidal cortical neurons as also observed in basal dendrites. However, the density of detectable spines appears to be higher in the Golgi-impregnated material. This could be due to methodological limitations, such as the penetration of the antibody for the detection of the RABV P-protein using CVS-11, and/or to heterogeneous spreading of the targeted RABV protein within the neuron. RABV tracing can nicely reveal the different morphologies of the distinct neuronal populations innervating a given brain region. Among the populations connecting the SN, first-order infected neurons in the subthalamic nucleus and the parafascicular thalamic nucleus are also illustrated (Figure 9A and 9B, respectively). One can note that these neurons are poorly spiny in comparison to striatonigral neurons even though their dendritic processes are well visualized, and that the subthalamic neurons are poorly branched compared to the rich arborization of parafascicular neurons.

The Golgi-like RABV tracing and its combination with other anatomical tools is an asset to reveal the levels of complexity in the anatomofunctional organisation of the studied circuitry and its remodelling in physiopathological conditions. For example, the striatum is organized into histochemically defined compartments termed matrix and striosomes (Graybiel and Ragsdale, 1978), whose specific connections and functions are still under scrutiny (Brimblecombe and Cragg, 2017; Smith et al., 2016). Previous work has examined the disposition of the dendritic processes of Golgi-stained neurons laying in either compartment with regards to the compartment boundaries in cat (Bolam et al., 1988). Here, using immunodetection of the mu opioid receptor to visualize the striosomes, we provide illustrations of the dendritic arbors of RABV-infected striatonigral neurons laying in either compartment in mice. In these examples, the arborizations of the neurons are markedly influenced by the compartment boundaries: the arborizations of the neurons in the matrix avoid the striosome, while the dendritic trees of the neurons in the striosomes remain mostly confined to this compartment (Figure 10), as also described in the rat nucleus accumbens after juxtacellular labeling (van Dongen et al., 2008). Quantitative analyses of such material, for example in terms of proportions of neurons identified from their target in either compartment, the respective spine densities of these neurons or the compartmentalization of their dendritic tree, could provide new insights onto organizational principles underlying striatal functions. In the same vein, the combination of retrograde RABV tracing with the anterograde tracing of striatal input systems (López et al., 2010; Salin et al., 2008) and the use of the transsynaptic spread of the virus combined with neurochemical identification of the interneurons connecting the primary-infected projection neurons have demonstrated their added value to explore the striatal microcircuits (Salin et al., 2009). On the one hand, the definition of the postsynaptic element achieved by the Golgi-like labeling of identified striatofugal neurons with RABV enabled the analysis at confocal microscopy level of the potential contacts they receive from anterogradely-labeled cortical and thalamic afferents. On the other hand, the unequivocal characterization of second-order interneurons showed that striatonigral and striatopallidal neurons are connected by equivalent numbers of parvalbumin interneurons, the same holding true for cholinergic interneurons. Recently, an approach combining the use of a newly developed anterograde RABV $\triangle \mathrm{G}$ variant and of a retrograde $\mathrm{RABV} \Delta \mathrm{G}$ to address reciprocal connectivity through long ranging pathways has been reported to 
enable the high-resolution reconstruction of key neuronal morphological features (dendrites, spines, boutons) (Haberl et al., 2017). The level of resolution of the RABV-based tracing approaches also allows addressing the plasticity of the neural networks. For example, evidence has been previously provided for a reorganization of the connections between striatal cholinergic interneurons and the two populations of striatal projection neurons in a rat model of Parkinson's disease (Salin et al., 2009). As another example, it is known that striatal spiny neurons undergo pruning and remodelling in patients with Parkinson's disease and animal models but data regarding the population affected, D2 and/or D1 dopamine receptor expressing neurons are controversial (for review see Villalba \& Smith, 2018). Integrating the dimension of striatal compartmentalization and associated input specificity might help to reconcile such discrepant observations. Using monosynaptic RABV tracing, adaptations in dendritic spine density at different stages of cocaine administration and withdrawal have been evidenced in distinct brain areas projecting to the subpopulations of D1- and D2-expressing neurons in the nucleus accumbens (Barrientos et al., 2018). Developmental issues have been also addressed as illustrated in a report showing default of pruning within intracortical circuits in mice deficient for candidate molecules involved in activity-regulated process needed for proper circuit sculpting (Adelson et al., 2016).

\subsection{Advantages and limitations of RABV tract-tracing}

Beside its Golgi-like staining property and compatibility with other tracing tools, RABV has many advantages over other retrograde neuronal tracers. Most in vivo studies report strict preference of Labadapted RABV for neurons compared to other CNS cells, in contrast to PRV, while glia infection has occasionally been noted with street RABV. Recent work evidenced astrocyte infection in vivo by field RABVs independent of the inoculation route (intramuscular or intracerebral) and for Lab-adapted RABV depending on strain and route (astrocyte infection frequency of 13\% after intracerebral rCVS11 , while $0 \%$ with two other lab RABV strains) (Potratz et al., 2020). However, this analysis has been performed in clinically-diseased animals at a late stage of infection (up to 21 days post-inoculation), which is outside the time window post-inoculation usually used for transsynaptic tracing purpose. RABV infects neurons only via synapses without uptake contamination of the passing fibers crossing the injection site. RABV is considered to move exclusively backwards (retrograde) and to propagate between interconnected neurons without inducing apparent inflammation or cell death up to 4 days post-injection (Ugolini, 2010). Evidence has been provided for morphological alteration or degeneration of specific neuronal types, but within several days after injection of the unmodified CVS-11 (Ruigrok et al., 2016), and after 16 days for SAD $\Delta$ G-EGFP (Wickersham et al., 2007a). Single cell RNA sequencing and immunodetection of glial markers provided evidence that RABV$\triangle$ G-EGFP can lead within 2 weeks to alterations in gene expression, mainly genes associated with the immune response, as well as microglial reaction at the injection site and in retrogradely labeled structures (Sun et al., 2019). However, as illustrated here, intracerebral RABV inoculation is able to reveal neurons connected to primary infected neurons (second-order) in less than 2 days, and even higher-order neurons within 3 days, providing an extended safe exploration window for depicting multisynaptic brain circuits. The rapid uptake of RABV is a factor limiting its spreading and thus the number of neurons infected from the injection site, as compared to conventional retrograde tracers, such as CTB. A major limitation in the use of transsynaptic tracers is the ambiguity in the determination of monosynaptic connections due to their incapacity to distinguish weak direct connections from strong indirect ones, which is overcome with the approaches using monosynaptic restriction of transsynaptic tracing. Other limitations have been stressed regarding the use of RABV to identify chains of connected neurons. It has been reported that RABV is unable to infect neurons via electrical synapses (gap junctions) (Tang et al., 1999), showing that the virus propagates only at chemical synapses. Moreover, several studies have reported failure of primary infection or of transneuronal transfer for identified neuronal populations (Albisetti et al., 2017; Ruigrok et al., 2016). In the basal ganglia, we also reported that striatal interneurons expressing neuronal nitric oxide synthase that are known to co-express somatostatin and neuropeptide $\mathrm{Y}$ are not second-order labeled after RABV infection of striatal efferent neurons (Salin et al., 2009). Finally, a recent study shows that retrograde viral tracers, including RABV and PRV, exhibit different patterns of neurotropism, 
outlining the importance of the appropriate virus selection for the neural networks to be dissected (Sun et al., 2019).

In conclusion, the pitfalls in the use of RABV as a transsynaptic retrograde tracer are balanced by its remarkable advantages to study morphology and connectivity of large populations of neurons identified from their anatomical target. In our experimental conditions and study model, RABV is more potent than the Bartha strain of PRV. Among the RABV strains and variants tested, the poorest labeling, both numerically and qualitatively, is offered by rCVS-N2c-M-GFP. CVS-11, rCVS-N2c-PmCherry and SAD $\Delta$ G.eGFP all provide impressive Golgi-like staining of primary infected neurons, the greatest numbers of neurons being detected with rCVS-N2c-P-mCherry, followed by CVS-11 and then $\mathrm{SAD} \Delta \mathrm{G}$. rCVS-N2c-P-mCherry thus represents a new powerful transsynaptic fluorescent tracer for deciphering neuronal networks, with the limitations and advantages inherent to its transsynaptic properties.

\section{Author contributions}

PC and DB provided viral materials and tools for detection. P.S. and P.C. performed the experiments. PS and L.K-L.G. conceptualized the study and prepared data and figures. All authors contributed to the paper writing.

\section{Declaration of Competing Interest}

None.

\section{Acknowledgments}

This work was supported by the Centre National de la Recherche Scientifique (CNRS) and AixMarseille Université (AMU). Microscopy was performed at the imaging platform of the IBDM, supported by the ANR through the 'Investments for the Future' program (France-BioImaging, ANR10-INSB-04-01). The authors especially thank the staffs of the imaging facilities for expert technical assistance. The IBDM and INT are affiliated with NeuroMarseille, the AMU neuroscience network, and with NeuroSchool, the AMU graduate school in neuroscience supported by the A*MIDEX foundation and the 'Investissements d'Avenir' program (nEURo*AMU, ANR-17-EURE-0029 grant). The authors thank J Nikolic for the construction of the fluorescent recombinant rCVS N2C and JA Rathelot for his expert assistance within the technological platform ConnectoVir at INT.

\section{References}

Ade, K.K., Wan, Y., Chen, M., Gloss, B., Calakos, N., 2011. An improved BAC transgenic fluorescent reporter line for sensitive and specific identification of striatonigral medium spiny neurons. Front. Syst. Neurosci. 5, 1-9. https://doi.org/10.3389/fnsys.2011.00032

Adelson, J.D., Sapp, R.W., Brott, B.K., Lee, H., Miyamichi, K., Luo, L., Cheng, S., Djurisic, M., Shatz, C.J., 2016. Developmental Sculpting of Intracortical Circuits by MHC Class i H2-Db and H2-Kb. Cereb. Cortex 26, 1453-1463. https://doi.org/10.1093/cercor/bhu243

Albin, R.L., Young, A.B., Penney, J.B., 1989. The functional anatomy of basal ganglia disorders. Trends Neurosci. 12, 366-375. https://doi.org/10.1016/0166-2236(89)90074-X

Albisetti, G.W., Ghanem, A., Foster, E., Conzelmann, K.K., Zeilhofer, H.U., Wildner, H., 2017. Identification of two classes of somatosensory neurons that display resistance to retrograde infection by rabies virus. J. Neurosci. 37, 10358-10371.

https://doi.org/10.1523/JNEUROSCI.1277-17.2017 
Alexander, G.E., Crutcher, M.D., 1990. Functional architecture of basal ganglia circuits: neural substrates of parallel processing. Trends Neurosci. 13, 266-271. https://doi.org/10.1016/01662236(90)90107-L

Astic, L., Saucier, D., Coulon, P., Lafay, F., Flamand, A., 1993. The CVS strain of rabies virus as transneuronal tracer in the olfactory system of mice. Brain Res. 619, 146-156. https://doi.org/10.1016/0006-8993(93)91606-S

Aston-Jones, G., Card, J.P., 2000. Use of pseudorabies virus to delineate multisynaptic circuits in brain: Opportunities and limitations. J. Neurosci. Methods 103, 51-61. https://doi.org/10.1016/S0165-0270(00)00295-8

Barrientos, C., Knowland, D., Wu, M.M.J., Lilascharoen, V., Huang, K.W., Malenka, R.C., Lim, B.K., 2018. Cocaine-Induced Structural Plasticity in Input Regions to Distinct Cell Types in Nucleus Accumbens. Biol. Psychiatry 84, 893-904. https://doi.org/10.1016/j.biopsych.2018.04.019

Berry, K.P., Nedivi, E., 2017. Spine Dynamics: Are They All the Same? Neuron 96, 43-55. https://doi.org/10.1016/j.neuron.2017.08.008

Bishop, G.A., Chang, H.T., Kitai, S.T., 1982. Morphological and physiological properties of neostriatal neurons: An intracellular horseradish peroxidase study in the rat. Neuroscience 7, 179-191. https://doi.org/10.1016/0306-4522(82)90159-2

Bolam, J.P., Izzo, P.N., Graybiel, A.M., 1988. Cellular substrate of the histochemically defined striosome/matrix system of the caudate nucleus: A combined golgi and immunocytochemical study in cat and ferret. Neuroscience 24, 853-875. https://doi.org/10.1016/0306-4522(88)900735

Brimblecombe, K.R., Cragg, S.J., 2017. The Striosome and Matrix Compartments of the Striatum: A Path through the Labyrinth from Neurochemistry toward Function. ACS Chem. Neurosci. 8, 235-242. https://doi.org/10.1021/acschemneuro.6b00333

Brown, J., Pan, W.X., Dudman, J.T., 2014. The inhibitory microcircuit of the substantia nigra provides feedback gain control of the basal ganglia output. Elife 2014, 1-25. https://doi.org/10.7554/eLife.02397

Burke, D.A., Rotstein, H.G., Alvarez, V.A., 2017. Striatal Local Circuitry: A New Framework for Lateral Inhibition. Neuron 96, 267-284. https://doi.org/10.1016/j.neuron.2017.09.019

Cajal, S.R., 1893. La rétine des vertébrés. Cellule 9, 119-257.

Cajal, S.R., 1888. Estructura de los centros nerviosos de las aves. Rev. Trim. Histol. Norm. Pat. 1, 110.

Calabresi, P., Picconi, B., Tozzi, A., Ghiglieri, V., Di Filippo, M., 2014. Direct and indirect pathways of basal ganglia: A critical reappraisal. Nat. Neurosci. 17, 1022-1030. https://doi.org/10.1038/nn.3743

Callaway, E.M., 2008. Transneuronal circuit tracing with neurotropic viruses. Curr. Opin. Neurobiol. https://doi.org/10.1016/j.conb.2009.03.007

Callaway, E.M., Luo, L., 2015. Monosynaptic circuit tracing with glycoprotein-deleted rabies viruses. J. Neurosci. 35, 8979-8985. https://doi.org/10.1523/JNEUROSCI.0409-15.2015

Card, J.P., Enquist, L.W., 2014. Transneuronal circuit analysis with pseudorabies viruses. Curr. Protoc. Neurosci. 68, 1.5.1-39. https://doi.org/10.1002/0471142301.ns0105s68

Card, J.P., Rinaman, L., Schwaber, J.S., Miselis, R.R., Whealy, M.E., Robbins, A.K., Enquist, L.W., 1990. Neurotropic properties of pseudorabies virus: Uptake and transneuronal passage in the rat central nervous system. J. Neurosci. 10, 1974-1994. https://doi.org/10.1523/jneurosci.10-0601974.1990 
Ceccaldi, P.E., Fayet, J., Conzelmann, K.K., Tsiang, H., 1998. Infection characteristics of rabies virus variants with deletion or insertion in the pseudogene sequence. J. Neurovirol. 4, 115-119. https://doi.org/10.3109/13550289809113489

Conzelmann, K.K., Cox, J.H., Schneider, L.G., Thiel, H.J., 1990. Molecular cloning and complete nucleotide sequence of the attenuated rabies virus SAD B19. Virology 175, 485-499. https://doi.org/10.1016/0042-6822(90)90433-R

Coulon, P., Bras, H., Vinay, L., 2011. Characterization of last-order premotor interneurons by transneuronal tracing with rabies virus in the neonatal mouse spinal cord. J. Comp. Neurol. 519, 3470-3487. https://doi.org/10.1002/cne.22717

De Groot, J., 1959. The rat forebrain in stereotaxic coordinates, 1st ed. N. V. Noord-Hollansche Uitgevers Maatschappij, Amsterdam.

Etessami, R., Conzelmann, K.K., Fadai-Ghotbi, B., Natelson, B., Tsiang, H., Ceccaldi, P.E., 2000. Spread and pathogenic characteristics of a G-deficient rabies virus recombinant: An in vitro and in vivo study. J. Gen. Virol. 81, 2147-2153. https://doi.org/10.1099/0022-1317-81-9-2147

Feng, G., Mellor, R.H., Bernstein, M., Keller-Peck, C., Nguyen, Q.T., Wallace, M., Nerbonne, J.M., Lichtman, J.W., Sanes, J.R., 2000. Neurotechnique Imaging Neuronal Subsets in Transgenic Mice Expressing Multiple Spectral Variants of GFP variants with altered spectral properties and improved translational efficiency, thermostability, and quantum yield. As a result of these favorable pro. Neuron 28, 41-51.

Fouquet, B., Nikolic, J., Larrous, F., Bourhy, H., Wirblich, C., Lagaudrière-Gesbert, C., Blondel, D., 2015. Focal Adhesion Kinase Is Involved in Rabies Virus Infection through Its Interaction with Viral Phosphoprotein P. J. Virol. 89, 1640-1651. https://doi.org/10.1128/jvi.02602-14

Gerfen, C.R., Scott Young, W., 1988. Distribution of striatonigral and striatopallidal peptidergic neurons in both patch and matrix compartments: an in situ hybridization histochemistry and fluorescent retrograde tracing study. Brain Res. 460, 161-167. https://doi.org/10.1016/00068993(88)91217-6

Graham, S.C., Assenberg, R., Delmas, O., Verma, A., Gholami, A., Talbi, C., Owens, R.J., Stuart, D.I., Grimes, J.M., Bourhy, H., 2008. Rhabdovirus matrix protein structures reveal a novel mode of self-association. PLoS Pathog. 4. https://doi.org/10.1371/journal.ppat.1000251

Graybiel, A.M., Ragsdale, C.W., 1978. Histochemically distinct compartments in the striatum of human, monkey, and cat demonstrated by acetylthiocholinesterase staining. Proc. Natl. Acad. Sci. U. S. A. 75, 5723-5726. https://doi.org/10.1073/pnas.75.11.5723

Haberl, M.G., Ginger, M., Frick, A., 2017. Dual anterograde and retrograde viral tracing of reciprocal connectivity, in: Methods in Molecular Biology. Humana Press Inc., pp. 321-340. https://doi.org/10.1007/978-1-4939-6688-2_21

Hagendorf, N., Conzelmann, K.K., 2015. Recombinant fluorescent rabies virus vectors for tracing neurons and synaptic connections. Cold Spring Harb. Protoc. 2015, 1058-1063. https://doi.org/10.1101/pdb.top089391

Jellinger, K.A., 2019a. Neuropathology and pathogenesis of extrapyramidal movement disorders: a critical update-I. Hypokinetic-rigid movement disorders. J. Neural Transm. https://doi.org/10.1007/s00702-019-02028-6

Jellinger, K.A., 2019b. Neuropathology and pathogenesis of extrapyramidal movement disorders: a critical update. II. Hyperkinetic disorders. J. Neural Transm. https://doi.org/10.1007/s00702-01902030-y

Jöns, A., Mettenleiter, T.C., 1997. Green fluorescent protein expressed by recombinant pseudorabies virus as an in vivo marker for viral replication. J. Virol. Methods 66, 283-292. 
https://doi.org/10.1016/S0166-0934(97)00065-7

Kim, E.J., Jacobs, M.W., Ito-Cole, T., Callaway, E.M., 2016. Improved Monosynaptic Neural Circuit Tracing Using Engineered Rabies Virus Glycoproteins. Cell Rep. 15, 692-699. https://doi.org/10.1016/j.celrep.2016.03.067

Lahaye, X., Vidy, A., Pomier, C., Obiang, L., Harper, F., Gaudin, Y., Blondel, D., 2009. Functional characterization of Negri bodies (NBs) in rabies virus-infected cells: Evidence that NBs are sites of viral transcription and replication. J. Virol. 83, 7948-58. https://doi.org/10.1128/JVI.00554-09

Lanciego, J.L., Wouterlood, F.G., 2020. Neuroanatomical tract - tracing techniques that did go viral, Brain Structure and Function. Springer Berlin Heidelberg. https://doi.org/10.1007/s00429-02002041-6

López, I.P., Salin, P., Kachidian, P., Barroso-Chinea, P., Rico, A.J., Gómez-Bautista, V., ContePerales, L., Coulon, P., Goff, L.K. Le, Lanciego, J.L., 2010. The added value of rabies virus as a retrograde tracer when combined with dual anterograde tract-tracing. J. Neurosci. Methods 194, 21-27. https://doi.org/10.1016/j.jneumeth.2010.01.015

Macpherson, T., Hikida, T., 2019. Role of basal ganglia neurocircuitry in the pathology of psychiatric disorders. Psychiatry Clin. Neurosci. 73, 289-301. https://doi.org/10.1111/pcn.12830

Mailly, P., Charpier, S., Menetrey, A., Deniau, J.M., 2003. Three-dimensional organization of the recurrent axon collateral network of the substantia nigra pars reticulata neurons in the rat. J. Neurosci. 23, 5247-5257. https://doi.org/10.1523/jneurosci.23-12-05247.2003

Morimoto, K., Foley, H.D., McGettigan, J.P., Schnell, M.J., Dietzschold, B., 2000. Reinvestigation of the role of the rabies virus glycoprotein in viral pathogenesis using a reverse genetics approach. J. Neurovirol. 6, 373-381. https://doi.org/10.3109/13550280009018301

Morimoto, K., Hooper, D.C., Carbaugh, H., Fu, Z.F., Koprowski, H., Dietzschold, B., 1998. Rabies virus quasispecies: Implications for pathogenesis. Proc. Natl. Acad. Sci. U. S. A. 95, 3152-3156. https://doi.org/10.1073/pnas.95.6.3152

Morimoto, K., Hooper, D.C., Spitsin, S., Koprowski, H., Dietzschold, B., 1999. Pathogenicity of Different Rabies Virus Variants Inversely Correlates with Apoptosis and Rabies Virus Glycoprotein Expression in Infected Primary Neuron Cultures. J. Virol. 73, 510-518. https://doi.org/10.1128/jvi.73.1.510-518.1999

Naito, A., Kita, H., 1994. The cortico-nigral projection in the rat: an anterograde tracing study with biotinylated dextran amine. Brain Res. 637, 317-322. https://doi.org/10.1016/00068993(94)91252-1

Nikolic, J., Civas, A., Lama, Z., Lagaudrière-Gesbert, C., Blondel, D., 2016. Rabies Virus Infection Induces the Formation of Stress Granules Closely Connected to the Viral Factories. PLoS Pathog. 12, 1-27. https://doi.org/10.1371/journal.ppat.1005942

Nikolic, J., Le Bars, R., Lama, Z., Scrima, N., Lagaudrière-Gesbert, C., Gaudin, Y., Blondel, D., 2017. Negri bodies are viral factories with properties of liquid organelles. Nat. Commun. 8, 1-12. https://doi.org/10.1038/s41467-017-00102-9

Ohara, S., Inoue, K.I., Yamada, M., Yamawaki, T., Koganezawa, N., Tsutsui, K.I., Witter, M.P., Iijima, T., 2009. Dual transneuronal tracing in the rat entorhinal-hippocampal circuit by intracerebral injection of recombinant rabies virus vectors. Front. Neuroanat. 3, 1-11. https://doi.org/10.3389/neuro.05.001.2009

Paxinos, G., Franklin, K.B.J., 2001. The mouse brain in stereotaxic coordinates, Second Edi. ed. Academic Press, San Diego.

Porrero, C., Rubio-Garrido, P., Avendaño, C., Clascá, F., 2010. Mapping of fluorescent protein- 
expressing neurons and axon pathways in adult and developing Thy1-eYFP-H transgenic mice. Brain Res. 1345, 59-72. https://doi.org/10.1016/j.brainres.2010.05.061

Potratz, M., Zaeck, L., Christen, M., te Kamp, V., Klein, A., Nolden, T., Freuling, C.M., Müller, T., Finke, S., 2020. Astrocyte Infection during Rabies Encephalitis Depends on the Virus Strain and Infection Route as Demonstrated by Novel Quantitative 3D Analysis of Cell Tropism. Cells 9, 412. https://doi.org/10.3390/cells9020412

Quartarone, A., Cacciola, A., Milardi, D., Ghilardi, M.F., Calamuneri, A., Chillemi, G., Anastasi, G., Rothwell, J., 2019. New insights into cortico-basal-cerebellar connectome: clinical and physiological considerations. Brain 396-406. https://doi.org/10.1093/brain/awz310

Raux, H., Iseni, F., Lafay, F., Blondel, D., 1997. Mapping of monoclonal antibody epitopes of the rabies virus P protein. J. Gen. Virol. 78, 119-124. https://doi.org/10.1099/0022-1317-78-1-119

Reardon, T.R., Murray, A.J., Turi, G.F., Wirblich, C., Croce, K.R., Schnell, M.J., Jessell, T.M., Losonczy, A., 2016. Rabies Virus CVS-N2c $(\Delta \mathrm{G})$ Strain Enhances Retrograde Synaptic Transfer and Neuronal Viability. Neuron 89, 711-24. https://doi.org/10.1016/j.neuron.2016.01.004

Ruigrok, T.J.H., van Touw, S., Coulon, P., 2016. Caveats in transneuronal tracing with unmodified rabies virus: An evaluation of aberrant results using a nearly perfect tracing technique. Front. Neural Circuits 10, 1-19. https://doi.org/10.3389/fncir.2016.00046

Salin, P., Castle, M., Kachidian, P., Barroso-Chinea, P., López, I.P., Rico, A.J., Kerkerian-Le Goff, L., Coulon, P., Lanciego, J.L., 2008. High-resolution neuroanatomical tract-tracing for the analysis of striatal microcircuits. Brain Res. 1221, 49-58. https://doi.org/10.1016/j.brainres.2008.05.011

Salin, P., López, I.P., Kachidian, P., Barroso-Chinea, P., Rico, A.J., Gómez-Bautista, V., Coulon, P., Kerkerian-Le Goff, L., Lanciego, J.L., 2009. Changes to interneuron-driven striatal microcircuits in a rat model of Parkinson's disease. Neurobiol. Dis. 34, 545-552. https://doi.org/10.1016/j.nbd.2009.03.006

Schnell, M.J., Mebatsion, T., Conzelmann, K.K., 1994. Infectious rabies viruses from cloned cDNA. EMBO J. 13, 4195-4203. https://doi.org/10.1002/j.1460-2075.1994.tb06739.x

Smith, J.B., Klug, J.R., Ross, D.L., Howard, C.D., Hollon, N.G., Ko, V.I., Hoffman, H., Callaway, E.M., Gerfen, C.R., Jin, X., 2016. Genetic-Based Dissection Unveils the Inputs and Outputs of Striatal Patch and Matrix Compartments. Neuron 91, 1069-1084. https://doi.org/10.1016/j.neuron.2016.07.046

Soh, T.K., Whelan, S.P.J., 2015. Tracking the Fate of Genetically Distinct Vesicular Stomatitis Virus Matrix Proteins Highlights the Role for Late Domains in Assembly. J. Virol. 89, 11750-11760. https://doi.org/10.1128/jvi.01371-15

Sun, L., Tang, Y., Yan, K., Yu, J., Zou, Y., Xu, W., Xiao, K., Zhang, Z., Li, W., Wu, B., Hu, Z., Chen, K., Fu, Z.F., Dai, J., Cao, G., 2019. Differences in neurotropism and neurotoxicity among retrograde viral tracers. Mol. Neurodegener. 14, 1-24. https://doi.org/10.1186/s13024-019-03086

Suzuki, T., Morimoto, N., Akaike, A., Osakada, F., 2020. Multiplex Neural Circuit Tracing With GDeleted Rabies Viral Vectors. Front. Neural Circuits 13, 1-23. https://doi.org/10.3389/fncir.2019.00077

Tang, Y., Rampin, O., Giuliano, F., Ugolini, G., 1999. Spinal and brain circuits to motoneurons of the bulbospongiosus muscle: Retrograde transneuronal tracing with rabies virus. J. Comp. Neurol. 414, 167-192. https://doi.org/10.1002/(SICI)1096-9861(19991115)414:2<167::AIDCNE3>3.0.CO;2-P

Taverna, S., Ilijic, E., Surmeier, D.J., 2008. Recurrent collateral connections of striatal medium spiny neurons are disrupted in models of Parkinson's disease. J. Neurosci. 28, 5504-5512. 
https://doi.org/10.1523/JNEUROSCI.5493-07.2008

Ugolini, G., 2011. Rabies Virus as a Transneuronal Tracer of Neuronal Connections, 1st ed, Advances in Virus Research. Elsevier Inc. https://doi.org/10.1016/B978-0-12-387040-7.00010-X

Ugolini, G., 2010. Advances in viral transneuronal tracing. J. Neurosci. Methods 194, 2-20. https://doi.org/10.1016/j.jneumeth.2009.12.001

Ugolini, G., 1995. Specificity of rabies virus as a transneuronal tracer of motor networks: Transfer from hypoglossal motoneurons to connected second- order and higher order central nervous system cell groups. J. Comp. Neurol. 356, 457-480. https://doi.org/10.1002/cne.903560312

Ugolini, G., Kuypers, H.G.J.M., Strick, P.L., 1989. Transneuronal transfer of herpes virus from peripheral nerves to cortex and brainstem. Science (80-. ). 243, 89-91. https://doi.org/10.1126/science.2536188

Van Dongen, Y.C., Mailly, P., Thierry, A.M., Groenewegen, H.J., Deniau, J.M., 2008. Threedimensional organization of dendrites and local axon collaterals of shell and core medium-sized spiny projection neurons of the rat nucleus accumbens. Brain Struct. Funct. 213, 129-147. https://doi.org/10.1007/s00429-008-0173-5

Villalba, R.M., Smith, Y., 2018. Loss and remodeling of striatal dendritic spines in Parkinson's disease: from homeostasis to maladaptive plasticity? J. Neural Transm. https://doi.org/10.1007/s00702-017-1735-6

Watabe-Uchida, M., Zhu, L., Ogawa, S.K., Vamanrao, A., Uchida, N., 2012. Whole-Brain Mapping of Direct Inputs to Midbrain Dopamine Neurons. Neuron 74, 858-873. https://doi.org/10.1016/j.neuron.2012.03.017

Wickersham, I.R., Finke, S., Conzelmann, K.K., Callaway, E.M., 2007a. Retrograde neuronal tracing with a deletion-mutant rabies virus. Nat. Methods 4, 47-49. https://doi.org/10.1038/nmeth999

Wickersham, I.R., Lyon, D.C., Barnard, R.J.O., Mori, T., Finke, S., Conzelmann, K.K., Young, J.A.T., Callaway, E.M., 2007b. Monosynaptic Restriction of Transsynaptic Tracing from Single, Genetically Targeted Neurons. Neuron 53, 639-647. https://doi.org/10.1016/j.neuron.2007.01.033

Wirblich, C., Schnell, M.J., 2011. Rabies Virus (RV) Glycoprotein Expression Levels Are Not Critical for Pathogenicity of RV. J. Virol. 85, 697-704. https://doi.org/10.1128/jvi.01309-10

Wirblich, C., Tan, G.S., Papaneri, A., Godlewski, P.J., Orenstein, J.M., Harty, R.N., Schnell, M.J., 2008. PPEY Motif within the Rabies Virus (RV) Matrix Protein Is Essential for Efficient Virion Release and RV Pathogenicity. J. Virol. 82, 9730-9738. https://doi.org/10.1128/jvi.00889-08

Zhu, X., Lin, K., Liu, Q., Yue, X., Mi, H., Huang, X., He, X., Wu, R., Zheng, D., Wei, D., Jia, L., Wang, W., Manyande, A., Wang, J., Zhang, Z., Xu, F., 2019. Rabies Virus Pseudotyped with CVS-N2C Glycoprotein as a Powerful Tool for Retrograde Neuronal Network Tracing. Neurosci. Bull. 1-15. https://doi.org/10.1007/s12264-019-00423-3 


\section{Figure legends}

Figure 1. Schematic history of the major strains of rabies virus and of their variants used in laboratory settings for neural tract-tracing (A) and representation of the full-length cDNA recombinant plasmid prCVS-N2c (B). A. The cartoon depicts the major milestones (timeline not to scale) in the generation of the variants and recombinants of the two main rabies virus fixed strains lab-adapted from the street Challenge Virus Standard (CVS, upper panel) and Street-Alabama-Dufferin (SAD) virus (lower panel). B. The plasmid prCVS-N2c-P-mCherry (P-mch) differs from the parental genomic plasmid prCVS-N2c by fusion of the mch gene at the 3 ' end of the $\mathrm{P}$ gene. The plasmid prCVS-N2c-M-GFP differs from prCVS-N2c by insertion of the EGFP gene within the M gene after the residue 78. The sets of two restriction enzymes used to insert these modified genes in the genomic plasmid are indicated.

Figure 2. Transsynaptic retrograde tracing within the cortico-striatal circuitry after CVS injection in the substantia nigra (SN). A. Illustration of the labeling at the injection site in the $\mathrm{SN} 42 \mathrm{~h}$ after injection of CVS-11. The lower panel is a zoomed image of the boxed area (dashed line rectangle) in the upper image in which the SN is delineated by full line. The viral P-protein is detected by immunofluorescence. No immunolabeled cell body or neuritic network is seen; only limited, presumably nonspecific, labeling along the injection tract is observed. B. Schematic representation of two-neuron chains investigated. At $24 \mathrm{~h}$ first-order striatonigral neurons would be faintly stained. At $42 \mathrm{~h}$, the virus would self-amplify in the primary infected neurons and propagate to the neurons innervating them: the striatal staining would mostly include numerous intensely labeled first-order striatonigral neurons and few faintly labeled second-order interneurons, while the cortical staining would mostly represent second-order corticostriatal projection neurons. The very few first-order corticonigral neurons are not represented in the scheme. $\mathrm{C}$ and D. Illustrative images of the stains in the cerebral cortex (C) and the striatum (D) at $42 \mathrm{~h}$ post-injection of the rCVS-N2c-P-mCherry recombinant.

Figure 3. Images exemplifying the staining in the striatum (A) and the cerebral cortex (B) at 24 (A1, A2,B1), 42 (A3, B2) and $72 \mathrm{~h}$ (A4, B3) after injection of unmodified CVS-11 in the substantia nigra and immunodection of the viral P protein. At $24 \mathrm{~h}$, the staining is mainly limited to the cell bodies and primary dendrites of the first-order neurons in both structures and associated with Negri bodies. At 42 $\mathrm{h}$ most of the infected striatal neuronal and few of the infected cortical neurons exhibit extensive staining of their dendritic trees. At $72 \mathrm{~h}$, the labeling in the striatum is so huge that the neurons can no more be individualized, and in the cortex neurons in all the layers are infected. cc: corpus callosum; Cx: cerebral cortex; St: striatum.

Figure 4. Visualization of striatonigral (A) and striatopallidal (B) neurons at $42 \mathrm{~h}$ after injection of CVS-11 in their respective target in Drd1a-tdTomato line 6 mice. The striatal projection neurons are identified by immunofluorescence detection of the viral P-protein (pseudocolor: green; A1 and B1) and the D1-expressing striatal neurons are visualized by td-Tomato fluorescence (pseudocolor: red; A2 and B2). Merge images are shown in A3 and B3. As expected, the great majority of neurons traced from the substantia nigra are D1-positive, whereas those traced from the globus pallidus are D1negative. Arrow in A shows one of the few infected neurons that does not express D1 dopaminergic receptors. Arrow in B indicates one of the rare D1-expressing striatopallidal neurons observed. Scale bars: $50 \mu \mathrm{m}$

Figure 5. Illustrative images of the high resolution detection of the dendritic arborization of striatal medium-sized spiny neuron obtained $42 \mathrm{~h}$ after intranigral injection of different first-order or multisynaptic retrograde tracers. A. Bartha GFP-pseudorabies virus (pseudocolor: green). B. SAD $\triangle$ G.eGFP (pseudocolor: green). C. rCVS-N2c-P-mCherry (pseudocolor: red). D. rCVS-N2c-MGFP (pseudocolor: green), E. unmodified CVS-11 (immunodetection of the phosphoprotein; pseudocolor: green, Alexa Fluor 488). F. Alexa Fluor conjugate of cholera toxin B (pseudocolor: red, 

$\mu \mathrm{m}$

Figure 6. Images illustrating the relative quantities of infected striatonigral neurons visualized 42 after intranigral injection of SAD $\Delta$ G.eGFP (A), CVS-11 (B) and rCVS-N2c-P-mCherry (C). Striatal fields have been chosen after examination of all the injected animals showing substantial labeling in the dorsolateral striatum to illustrate the average numbers of infected neurons detected for each RABV vector. Scale bars: $50 \mu \mathrm{m}$

Figure 7. Enhanced staining of striatonigral neurons after intranigral injection of rCVS-N2c-M-GFP by immunodetection of the fusion-GFP or by immunodetection of the viral P protein. The native GFP fluorescence of the recombinant CVS shows only few and lightly stained neurons (pseudocolor: green; A1, B1). Amplification by immunodection of the GFP enhances the number of neurons well observable (pseudocolor: red; A2), while immunodetection of the viral P protein reveals the dendritic arbors in a Golgi staining-like fashion (pseudocolor: red; B2), as nicely shown in the merge images (A3, B3). Scale bars: $50 \mu \mathrm{m}$

Figure 8. Images illustrating the resolution provided by viral tracing using rCVS-N2c-P-mCherry (B) (pseudocolor: white), as compared to Golgi impregnation staining (A) for the visualization of striatal medium-sized spiny neurons (A1, B1), with magnification of a portion of dendritic arbors (A2, B2), and of cortical pyramidal neurons (A3, B3). The illustrations in B come from sections obtained $42 \mathrm{~h}$ after intranigral injection of the CVS recombinant.

Figure 9. Images of first-order neurons detected in the subthalamic nucleus (A) and the parafascicular thalamic nucleus (B) at $42 \mathrm{~h}$ after intranigral injection of the CVS recombinant rCVS-N2c-P-mCherry (pseudocolor: red). Scale bars: $20 \mu \mathrm{m}$

Figure 10. Disposition of the dendritic arborizations of striatonigral neurons in relationship with the striosome-matrix compartmentalization. The detection of striatonigral neurons by mCherry fluorescence (pseudocolor: magenta) at $42 \mathrm{~h}$ after intranigral injection of rCVS-N2c-P-mCherry is combined with immunostaining of the mu opioid receptor (pseudocolor: green) for visualizing the striosomes (delineated areas). A and B illustrate neurons whose dendritic arbors are mostly confined within the matrix or the striosomes, and then tend to respect the compartment boundaries. Scale bars: $20 \mu \mathrm{m}$ 

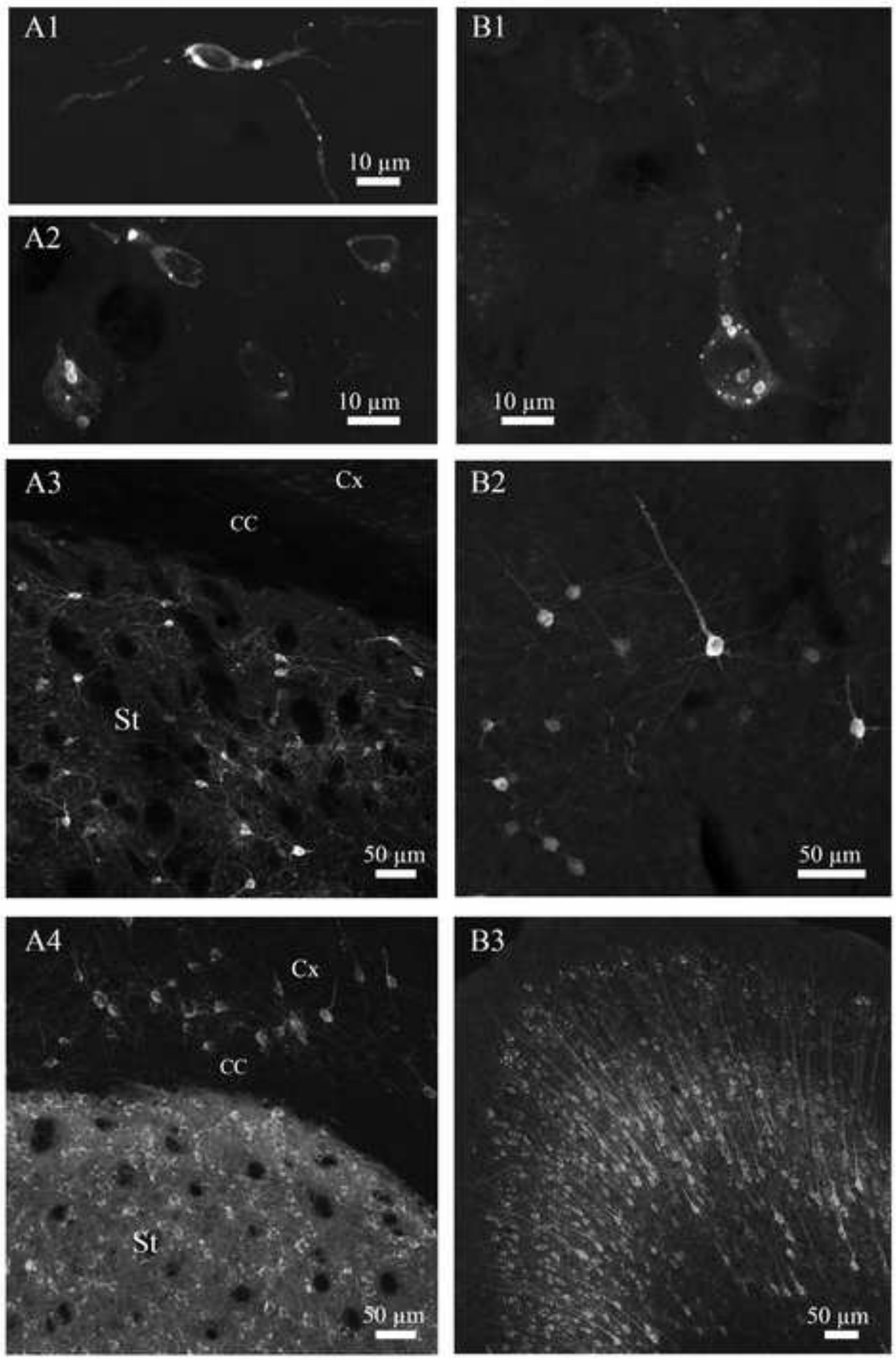

B3

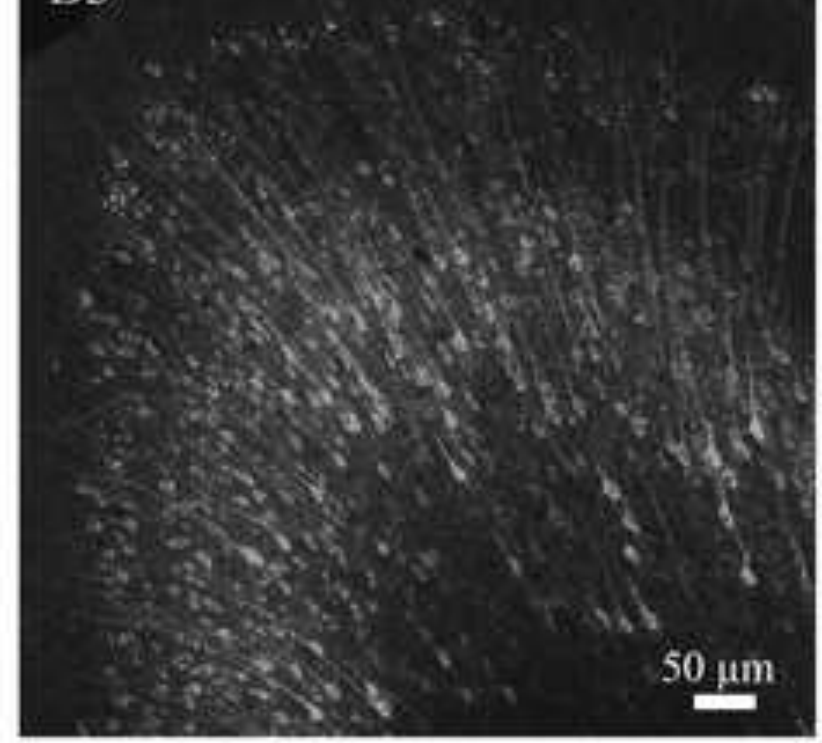


Click here to download high resolution image
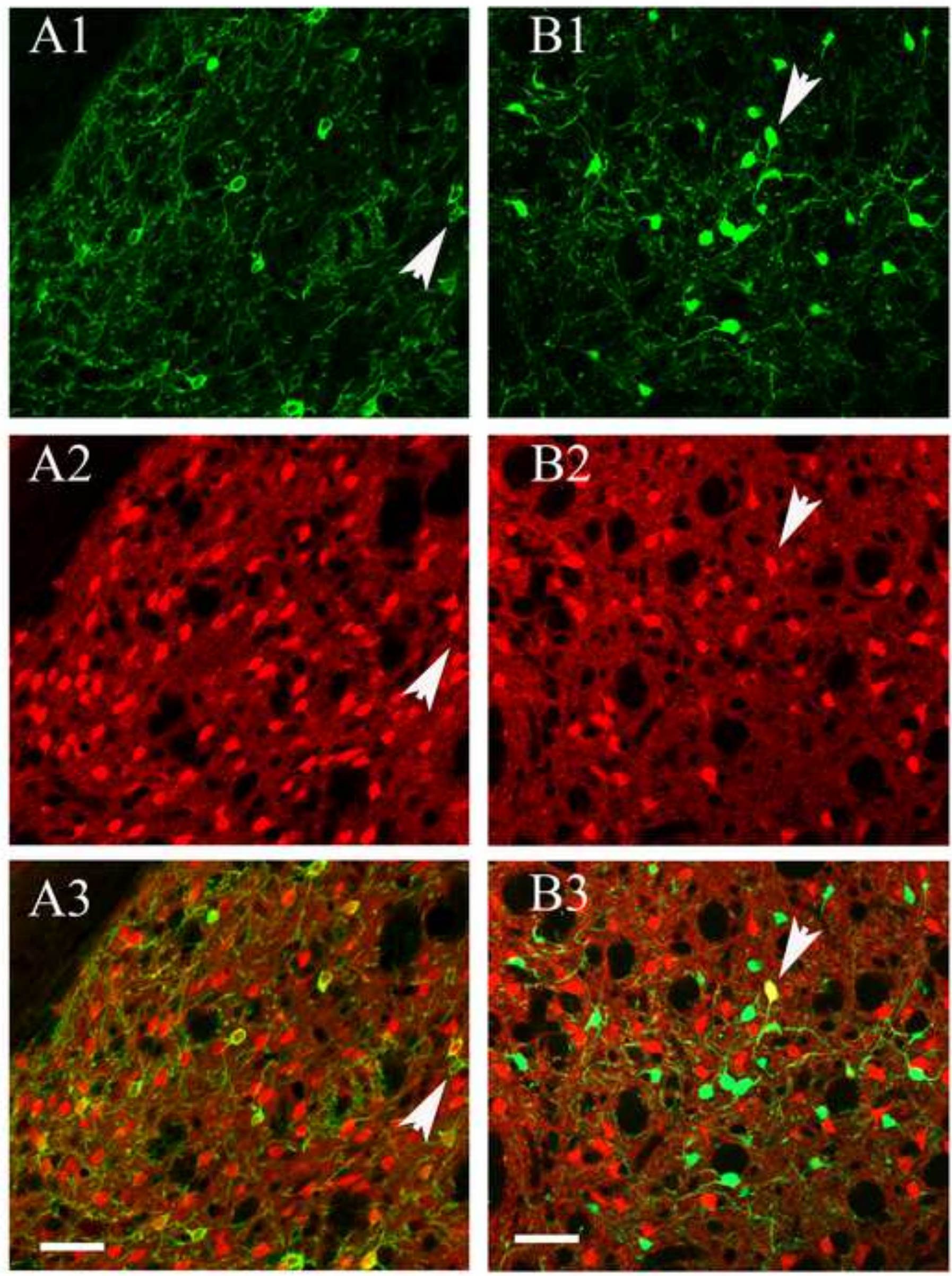
Fig 5 -salin et a

Click here to download high resolution image
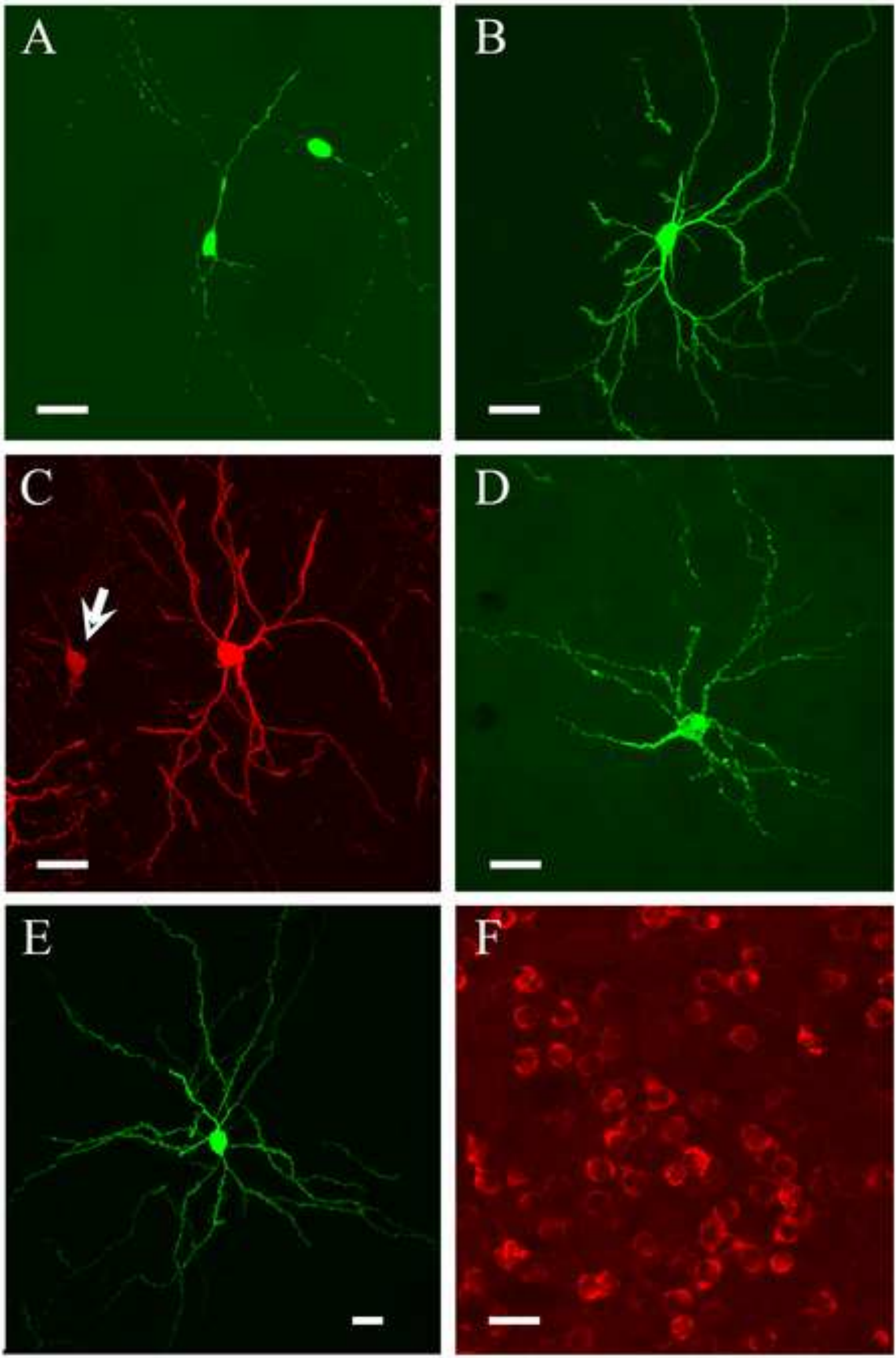
Fig 6 -salin et al
Click here to download high resolution image
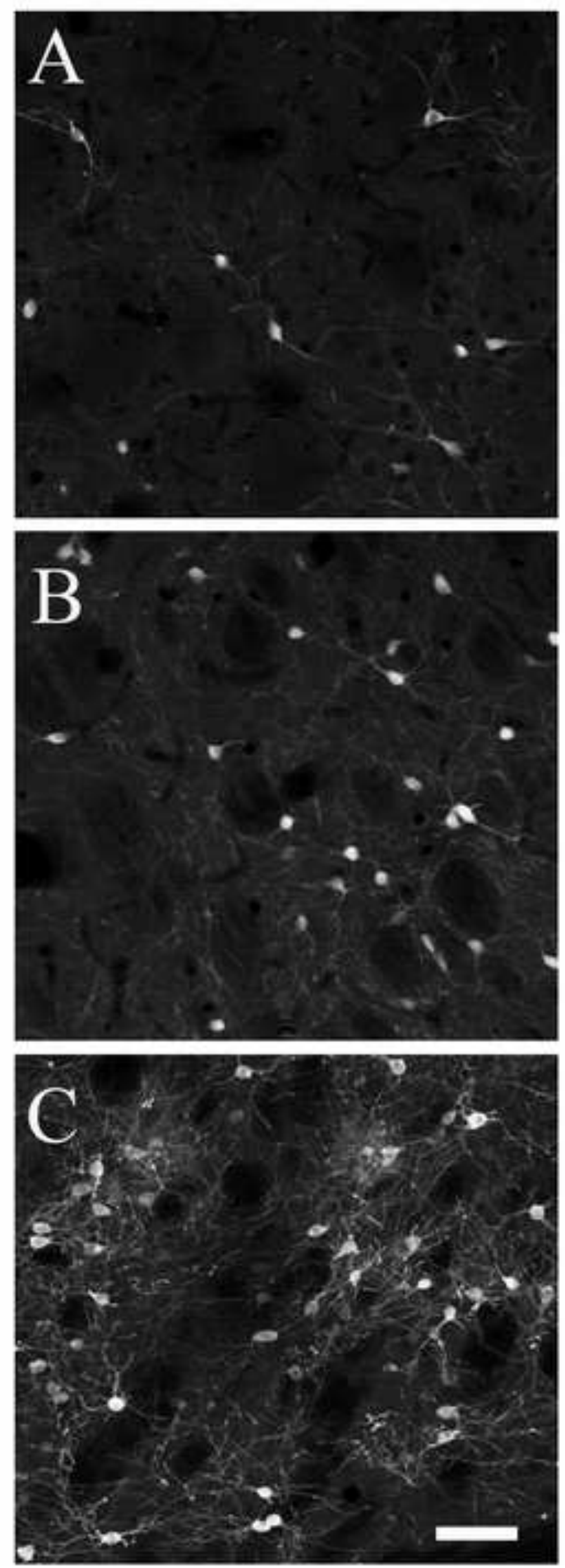


\section{Fig 7 -salin et al
Click here to download high resolution image}

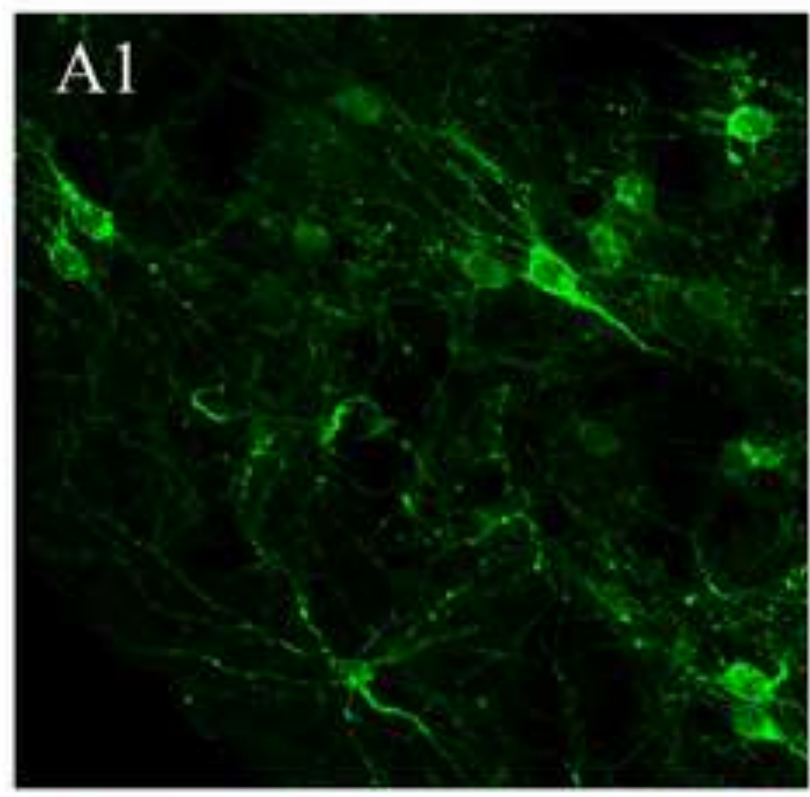

B1

82
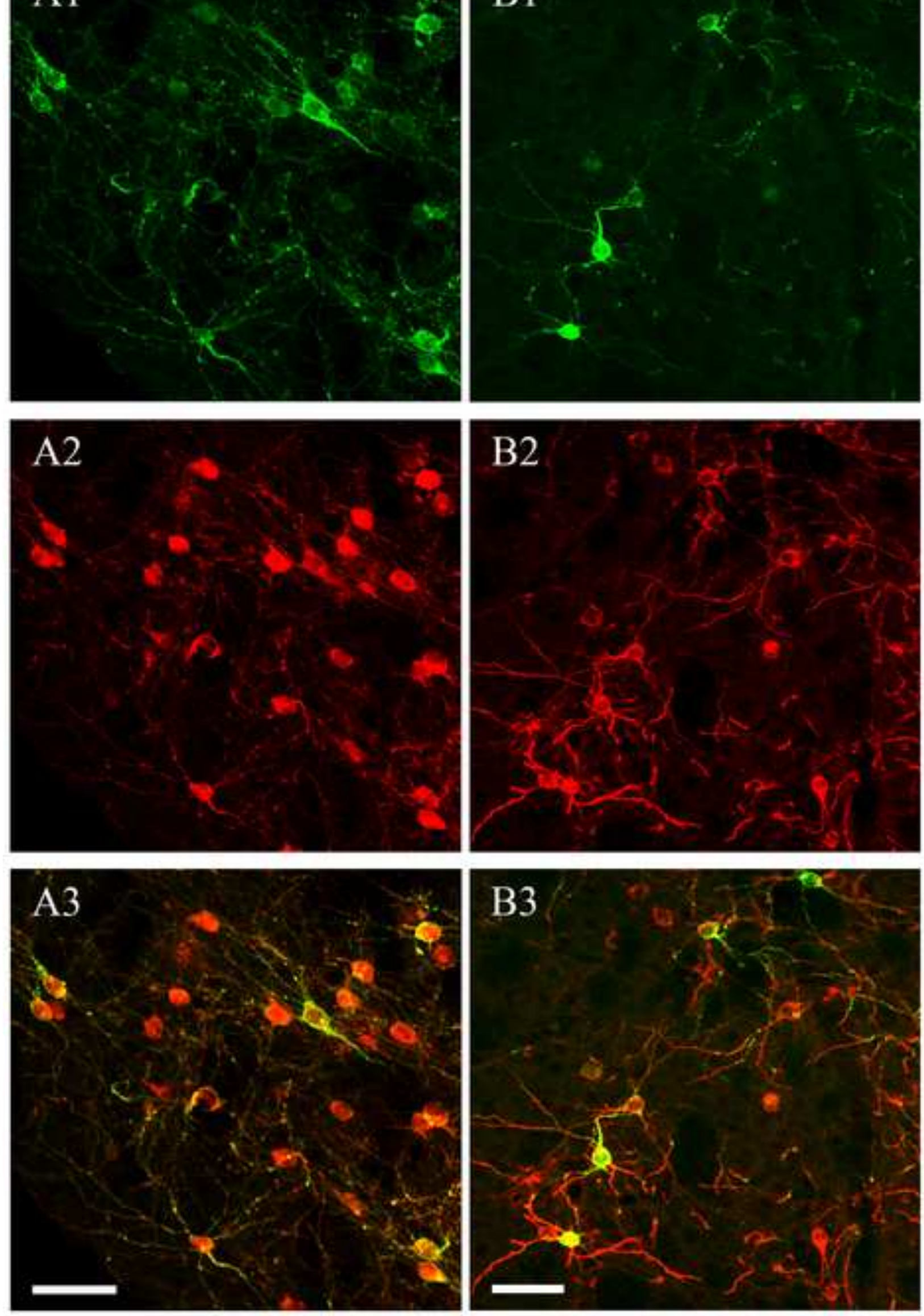


\section{Fig 8 -salin et al}

Click here to download high resolution image
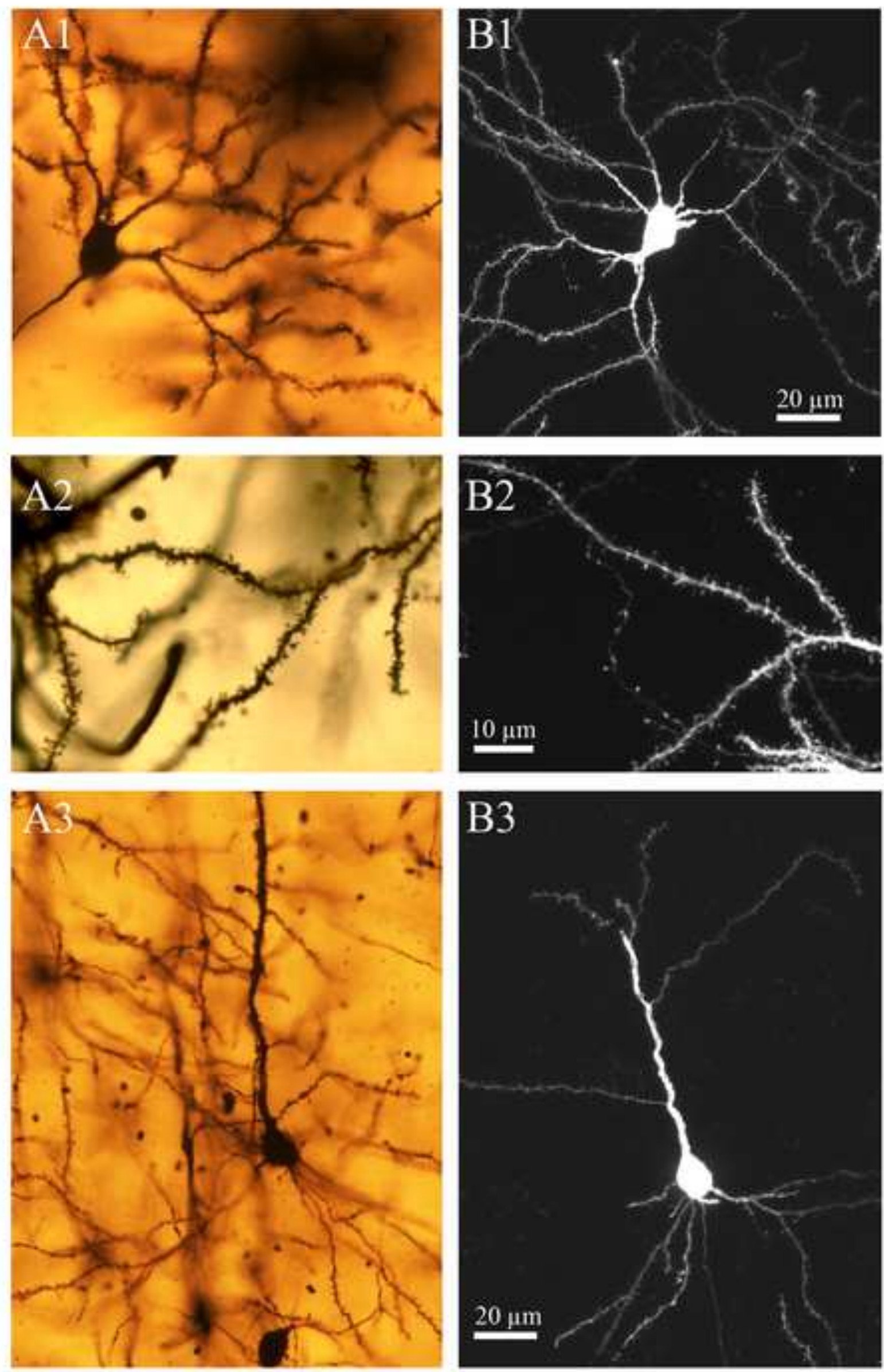
Fig 9 -salin et al
Click here to download high resolution image
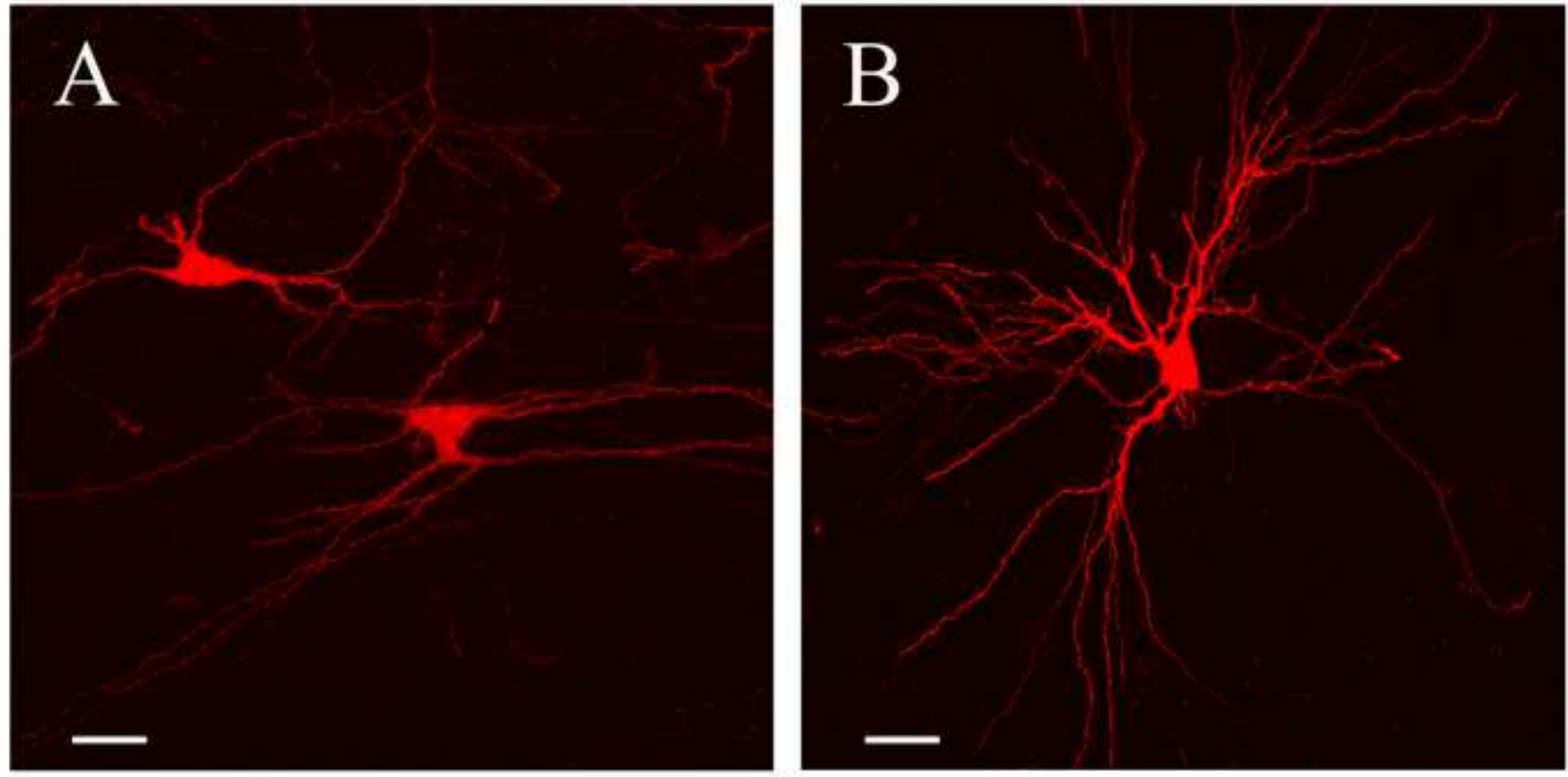

A

B 

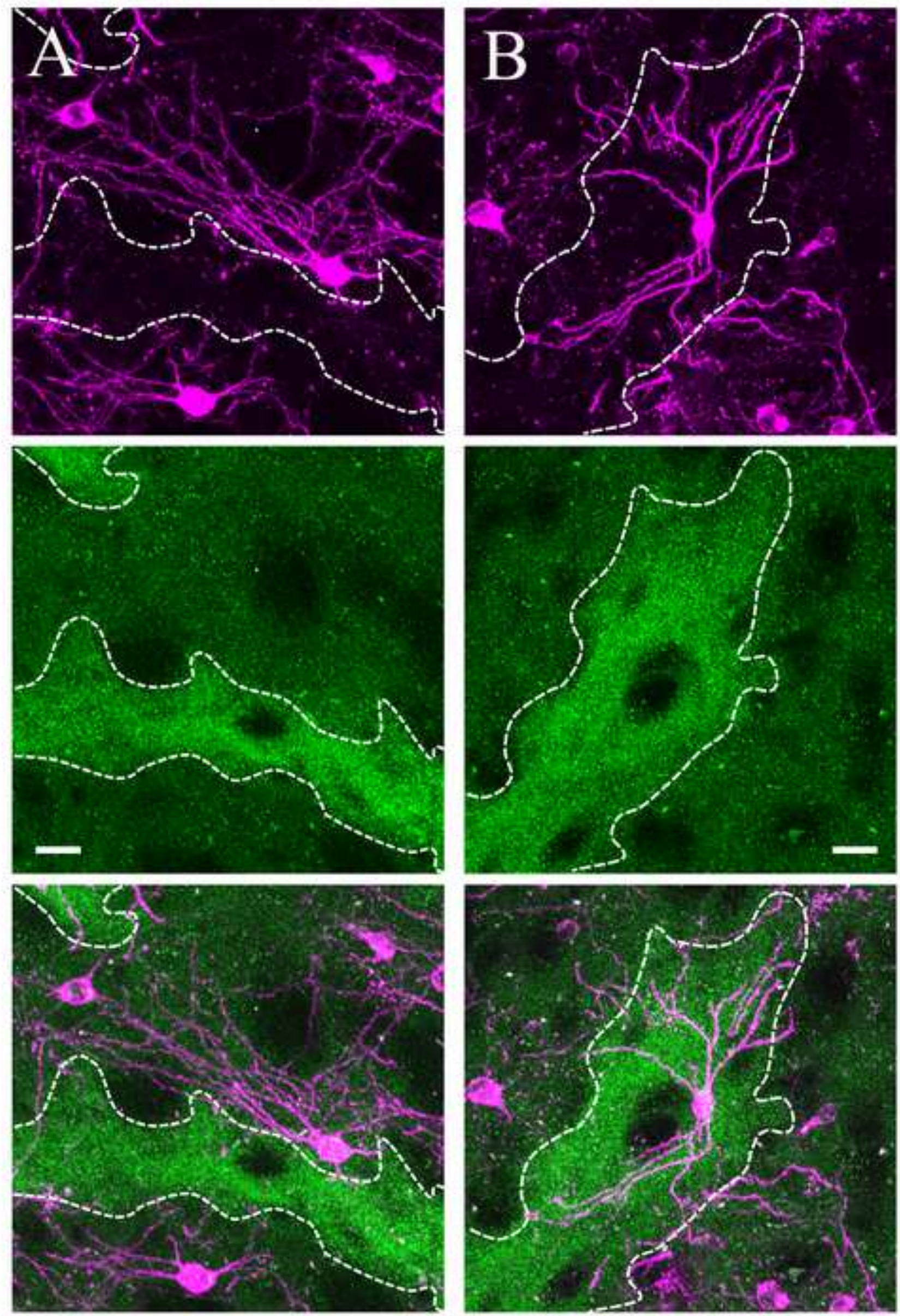